\title{
Propaganda, libertad de imprenta y circulación de las ideas: la influencia inglesa en el Mediterráneo (1794-1818)
}

\author{
Patrizia DE SALVO \\ Università degli Studi di Messina \\ pdesalvo@unime.it
}

Recibido: 10 de marzo de 2011

Aceptado: 22 de junio de 2012

\begin{abstract}
Resumen
La investigación se refiere a la creación de una información controlada por parte de Gran Bretaña, en el arco de tiempo que corre de 1790 a los alrededores de 1818 . La amplia circulación de ideas que caracterizó tal período, la progresiva difusión de la cultura, el nacimiento de "lugares de la sociabilidad" y el uso crecientemente difundido de periódicos y gacetas habilitaba a un público cada vez más amplio para constituirse en intérprete de las instancias del constitucionalismo moderno.

El contexto es, primero, de la guerra antijacobina, y después, del enfrentamiento con Napoleón en el area del Mediterráneo, desde el nacimiento del Reino Anglo-Corso hasta la formación de los Estados Unidos de las Islas Jonias. La idea de "guerra psicológica" aparece directamente enlazada con el concepto de opinión pública como sujeto político.
\end{abstract}

Palabras clave: constitucionalismo mediterráneo, prensa, propaganda, opinión pública, Gran Bretaña.

\section{Propaganda, printing freedom and circulation of ideas: the English influence in the Mediterranean World (1794-1818)}

\begin{abstract}
This contribution examines Britain's influence in the formation of a controlled information in the Mediterranean area from 1790 to 1818 . The wide circulation of ideas that characterized this period, the gradual spread of culture, the new 'spaces of sociability' and, finally, the increasingly widespread use of newspapers and gazettes, allowed to a widespread audience to become the interpreters of the postulates of modern constitutionalism. The historical background is the Anti-Jacobin War and the confrontation with Napoleon in the Mediterranean, from the founding of the Anglo-Corsican Kingdom in 1793 to the establishment of the United States of the Ionian Isles in 1815. This paper demonstrates how the idea of 'psychological warfare' appears directly linked to the concept of public opinion as a political subject.
\end{abstract}

Key words: euro-mediterranean Constitutionalism, newspapers, propaganda, public opinion, Great Britain. 


\section{PREMISA}

La investigación cuyos trazos más significativos intento ilustrar, y que se inserta a su vez en un más amplio filón de estudios sobre el constitucionalismo euro-mediterráneo, se refiere a la creación de una información controlada por parte de Gran Bretaña, en el arco de tiempo que corre de 1790 a los alrededores de 1818, en el contexto, primero, de la guerra antijacobina, y después, del enfrentamiento con Napoleón. La idea de "guerra psicológica" aparece directamente enlazada con el concepto de opinión pública como sujeto político.

Debo señalar cómo Nicola Matteucci, en la voz correspondiente incorporada a la Enciclopedia del Diritto, hizo explícita referencia a la dificultad de alcanzar una definición de aceptación general respecto a la noción de "opinión pública", cuando menos en lo que se refiere a los años en cuestión, entre otras cosas porque la expresión vino a utilizarse con acepciones diversas a tenor de disciplinas diversas, como por ejemplo la historia de las instituciones, la historia del pensamiento político, la teoría política y otras.

A los efectos de caracterización de tal concepto viene el adjetivo "pública", que asume un significado doble: es pública en cuanto a su formación, en el sentido -apunta Matteucci- de que se trata de una opinión no individual, que surge al compás de un debate y desemboca en un sentir común; y es pública porque tiene como sujeto la vida política en todos sus aspectos ${ }^{1}$.

El uso de la expresión "opinión pública" puede remontarse a Jacques Necker, que en su famoso Compte rendu au Roi (1781) hacía pública la desastrosa situación de las finanzas francesas, mientras que la formulación de tal concepto con el significado de guía y legitimación del poder político se tendrá, como es sabido, sólo en vísperas de la Revolución francesa, consagrándose en el artículo 11 de la Declaración de derechos del hombre y el ciudadano de 1789:

la libre comunicación de pensamientos y opiniones es uno de lo derechos más preciosos del hombre; así pues, todo ciudadano puede hablar, escribir, imprimir libremente, respondiendo del abuso de esta libertad en los casos determinados por las leyes.

No por casualidad Benjamin Constant localizó precisamente en la libertad de imprenta la apoyatura fundamental de la relación entre instituciones y opinión pública:

No son las formas las que hacen durar a las constituciones; una constitución no dura sin opinión pública, y no existe opinión pública sin libertad de imprenta. Cuando se ahoga esta libertad, los grandes cuerpos del Estado son como masas aisladas de la nación, desprovistos de vida y fuerza real...2.

1 Matteucci, N.: "Opinione pubblica”, Enciclopedia del Diritto, XXX (1980), pp. 420-430 (recogido luego en su Lo Stato Moderno. Lessico e Percorsi, Bolonia, Il Mulino, $2^{\mathrm{a}}$ ed. 1997, en concreto pp. 169-188, del cual hay versión española reciente, El Estado Moderno. Léxico y exploraciones, Madrid, Unión Editorial, 2010, con el trabajo indicado en pp. 179-200).

2 La cita puede leerse en LACCHÈ, L.: "Introduzione", Giornale di storia costituzionale, II semestre, 6 (2003), p. 5. 
Con el hecho de su formación, entonces, la opinión pública moderna sentaba definitivamente "las premisas para el nacimiento de una cultura de buen gobierno basada sobre una relación nueva entre la política y el derecho" y alcanzaba a crear un "espíritu público inspirado en principios de responsabilidad y participación en las decisiones políticas"3.

A la vista de tal orden de consideraciones, el análisis de los acontecimientos político-institucionales que han caracterizado el área del Mediterráneo en el paso del Setecientos a los primeros años del Ochocientos, y la reflexión acerca de su dinámica, permite captar la complejidad del proceso que, partiendo de la Revolución francesa, atravesaba de hecho la península italiana desde el antiguo régimen a los umbrales de los movimientos insurreccionales del siglo XIX.

La amplia circulación de ideas que caracterizó tal período, la progresiva difusión de la cultura, el nacimiento de "lugares de la sociabilidad" y el uso crecientemente difundido de periódicos y gacetas habilitaba a un público cada vez más amplio para constituirse en intérprete de las instancias del constitucionalismo moderno.

Concentrando mi análisis en el área del Mediterráneo, no se puede dejar de concretar una ulterior relación entre la formación de la opinión pública y la afirmación de la libertad de imprenta como derecho constitucionalmente garantizado, entre 1794 y 1817.

Desde este punto de vista, parece oportuna una relectura de determinados experimentos constitucionales partiendo de la consideración, propuesta por Ricotti, según la cual

las islas mediterráneas, Corcega, Malta, Sicilia, Islas Jonias cumplen, entre el Setecientos y el Ochocientos, la función de verdaderos y auténticos "laboratorios de ingeniería constitucional", en los cuales el legislador británico experimentaba formas e institutos de gobierno (tanto a nivel local como central), así como modelos administrativos y jurisdiccionales ${ }^{4}$.

De una atenta evaluación de tales circunstancias emergen determinadas problemáticas, ligadas a la circulación de las ideas, a la fecha todavía poco investigadas. A mi entender, resulta posible avanzar la hipótesis de la existencia de una estrecha conexión entre la presencia inglesa en el Mediterráneo y una política de información

3 Trampus, A.: Storia del costituzionalismo italiano nell'età dei Lumi, Bari-Roma, Laterza, 2009, p. VII.

4 Cfr. Ricotтi, C. R.: "Il costituzionalismo britannico nel Mediterraneo fra rivoluzione e restaurazione. Dal "modello corso" (1794) al "modello ionio" (1818)", en Romano, A. (ed.): Il modello costituzionale inglese e la sua recezione nell'area mediterranea tra la fine del settecento e la prima metà dell'ottocento, Atti delle giornate di studio in memoria di Francisco Tomás y Valiente, Milano, Giuffrè, 1998, p. 394. Sobre el constitucionalismo inglés en el área del Mediterraneo, RicotTI, C. R.: "Il costituzionalismo britannico nel Mediterraneo (1794-1818)", Clio, 3 (1991), pp. 365-451; RicotTI, C. R.: "Il costituzionalismo britannico nel Mediterraneo (1794-1818): II: Fra "whigs" e "tories": le istanze costituzionali a Malta", Clio, 2 (1993), pp. 213-282; Riсотті, C. R.: "Ancora sul modello corso; il sistema elettorale e la sua derivazione britannica", Clio, 4 (1993), pp. 579-607; por último, RicotтI, C. R.: Il costituzionalismo britannico nel Mediterraneo (17941818), Milano, Giuffrè, 2005. 
favorable a Gran Bretaña, basada sobre una propaganda con fines de guerra "de opinión pública" contra la Francia revolucionaria, primero, y napoleónica, después.

De hecho, me parece posible señalar en concreto, como común denominador entre las diversas constituciones promulgadas bajo auspicios ingleses y la constitucionalización de la libertad de imprenta, la consiguiente creación de experimentos editoriales originales 5 .

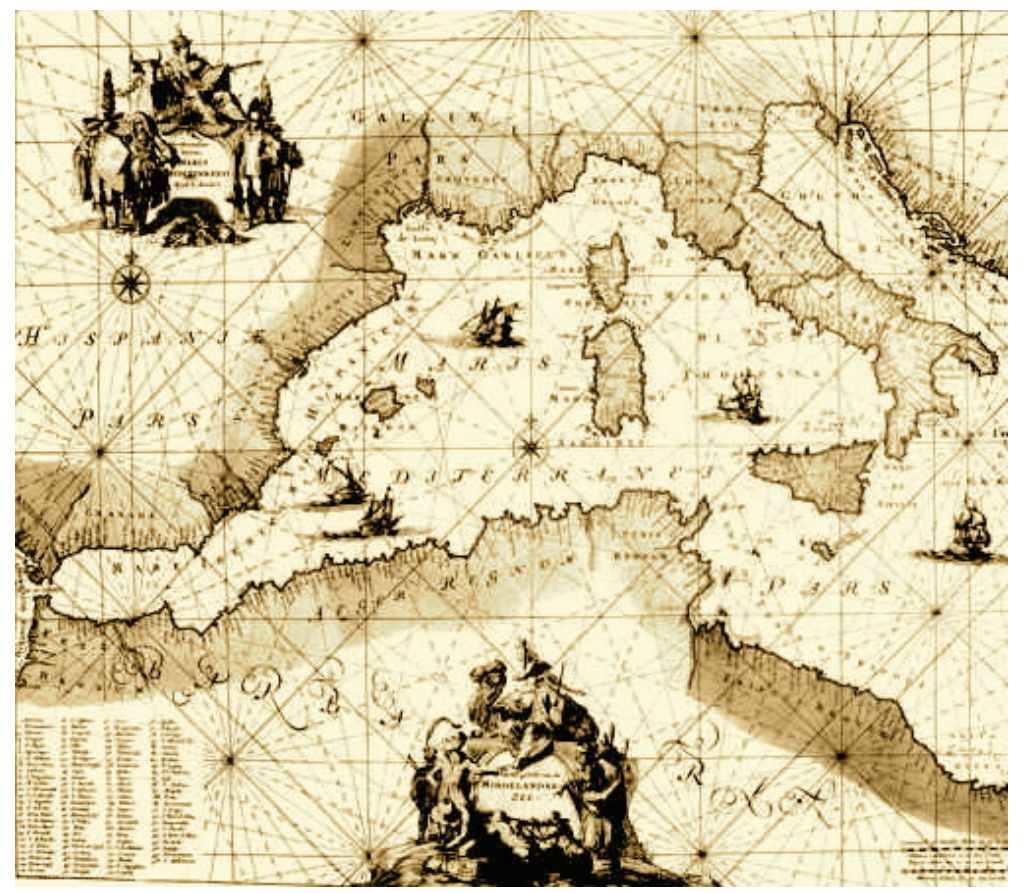

\section{EL REINO ANGLO-CORSO Y LA GAZZETTA CORSA}

No es mi intención reconstruir aquí la historia del Reino Anglo-Corso, ni proporcionar un cuadro completo de las cuestiones que ha suscitado. Mi propósito es algo más modesto: intentaré afrontar la problemática de la formación de una opinión pública, favorable a la presencia inglesa en la Isla, a la luz de la libertad de imprenta reconocida en la Carta constitucional emanada en 1794, en la medida de la exigüidad de los materiales recuperables.

5 En particular, la Constitución del Reino Anglo-Corso (1794), los proyectos constitucionales de Malta (1801-1802), la Constitución de Cádiz y la Carta siciliana de 1812 y la de los Estados Unidos de las Islas Jonias (1817). Daniela Novarese, mediante la lectura comparada de las constituciones elaboradas en el área del Mediterráneo, ha apuntado la conclusión de que hablar de "laboratorios de ingeniería constitucional" con referencia exclusiva a la presencia inglesa podría resultar reductivo; cfr., NovARESE, D.: "Tra Inghilterra e Francia. Dichiarazione e garanzie dei diritti fondamentali nel costituzionalismo europeo fra sette e ottocento", Società e storia, 99 (2003), pp. 31-44. 
El surgimiento del Reino Anglo-Corso en $1794^{6}$ puede ser considerado como momento inicial de la apuesta político militar mediante la cual la clase gobernante británica, y en particular el ala burkeana de los whigs, durante más de un ventenio, habría intentado "exportar" a Europa, sobre todo en el área mediterránea, los modelos e institutos del constitucionalismo inglés.

Tal campaña, que se originó en la necesidad de contención del expansionismo político e ideológico jacobino, pasó a desenvolverse luego contra la pretensión napoleónica de hegemonizar el continente?

Como es sabido, la salida de Pasquale Paoli del gobierno de Córcega y su sucesiva expulsión como "traidor a la Republica Francesa" provocó la revuelta de la isla y el desembarco de tropas inglesas en febrero de $1794^{8}$.

Paoli, fuertemente conmovido ante los excesos revolucionarios franceses, convocó a una Consulta en Corte, entonces capital de Córcega, y en junio del mencionado año declaró la separación total de la isla respecto a Francia, y el paso de la isla bajo el directo control del gobierno inglés, promulgando a su vez una Constitución que contemplaba exclusivamente un regimen de unión personal de la Isla y de Inglaterra bajo la común soberanía de Jorge III, garantizando a Córcega la autonomía.

El rey estaba representado localmente por un virrey, titular del poder ejecutivo y partícipe también del poder legislativo, en teoría atribuido al Parlamento, elegido mediante sistema censitario.

La lectura del texto muestra ya cómo éste, en determinados aspectos, puede representar el punto de encuentro entre las tradicciones isleñas, correspondientes al período comprendido entre 1755 y 1769, la experiencia llevada a madurez por Paoli con ocasión de su exilio en Inglaterra (factor de un cierto repliegue hacia posiciones moderadas), la praxis británica - tal y como ésta venía desenvolviéndose desde finales del siglo XVII- y sobre todo la voluntad inglesa de proponer a Europa un régimen constitucional "alternativo" respecto al que la Francia revolucionaría venía difundiendo en el continente. Así las cosas, el 19 de junio de 1794 Córcega se dotaba de una Constitución, enteramente escrita en italiano, que transformaba la isla en una

$6 \quad$ El texto de la Constitución Anglo-Corsa puede leerse en Aquarone, A., D’Addio, M., Negri, G.: Le Costituzioni italiane, Milano, Edizioni di Comunità, 1958, p. 715-720. Rovere, A.: "Patriottismo, costituzionalismo e Regno anglo-corso", Materiali per una storia della cultura giuridica, n. 1, XXVII (1997), pp. 19-31.

7 A tal efecto resultan pertinentes las "Actes du colloque sur le "Royaume anglo-corse" (1794-1796)", Bulletin de la Société des Sciences Historiques et Naturelles de la Corse, CXV, 670/671 (1995).

8 La actividad de Pasquale Paoli en Córcega tiene raíces remotas. Educado en el ambiente ilustrado napolitano de Gaetano Filangieri y Antonio Genovesi, Paoli había preparado desde tiempo atrás su reingreso con un papel decisivo en la isla. Dio una impronta irreversible a la revuelta corsa, gracias a la constitución elaborada en 1755, donde ya comparecían algunos de los aspectos más significativos del constitucionalismo del setecientos. La revolución paoliana supo hacerse con las simpatías y los apoyos de la intelectualidad ilustrada (así Rousseau, Boswell, Alfieri, Goethe). Contenía in nuce motivaciones, problemas y cuestiones que se presentarían de manera más cumplida en las grandes insurrecciones de finales del siglo XVIII. La isla figuraba un "pequeño laboratorio politico" observable desde realidades europeas más significativas. Rousseau, por ejemplo, leía en el caso de autogobierno corso la plasmación concreta de las teorías expuestas en el Contrato Social, y dedicaba a la isla su Proyecto de Constitución para Córcega, mientras Boswell y muchos otros ilustrados ingleses asimilaban la estructura administrativa puesta en planta por Pasquale Paoli, durante su mandato, al gobierno liberal británico (cfr. DAL PAsso, F.: Il Mediterraneo dei Lumi. Corsica e democrazia nella stagione delle rivoluzioni, Roma-Napoles, 2006; véase, además, Trampus, op. cit. (n. 3). 
Monarquía constitucional. El Rey pasaba a compartir el poder legislativo con los Representantes del pueblo, elegidos mediante sistema censitario, en un Parlamento unicameral (art. 2, Título I, De la naturaleza de la Constitución, y de los poderes que la componen), se instituía la figura de un virrey, como representante del soberano, por lo demás titular del poder ejecutivo (art. 1, Título V, Del ejercicio del poder ejecutivo). También la justicia emanaba del soberano, y sus órdenes se ejecutaban "por Agentes por éste nombrados, según Ley" (art. 1, Título VI, De la justicia, y de la división de los Tribunales). Una Constitución, pues, que remitiéndose al modelo inglés, aseguraba un amplio sistema de garantías individuales, confirmadas por la introducción del instituto del habeas corpus, del jury, del riconocimiento de la religión cristiana, católica apostólica y romana, "en toda su pureza evangélica", "como la única Nacional en Córcega" y de la libertad de conciencia ${ }^{10}$. En particular, la constitucionalización de las libertades individuales y de la libertad de imprenta ${ }^{11}$, "decretada, respondiéndose por su abuso a tenor de la ley”, garantizada en el Título VIII, hacía posible en la Isla la eclosión de una publicística antifrancesa intensamente conectada a dicho momento constitucional, por lo demás breve (1794-1796). Se trataba, por tanto, "de una de las primeras tentativas de exportación hacia el Mediterráneo del modelo constitucional inglés de una forma del todo inédita, esto es, transformándolo en constitución escrita, en el cuadro de lo que ha podido ser descrito como un proceso de modernización de las constituciones históricas" 12

Córcega no había permanecido extraña a la difusión de cierto periodismo político incluso antes de la promulgación de la Carta constitucional: de hecho, en la Isla ya venía actuando Filippo Buonarroti ${ }^{13}$, figura periodística notable en la Toscana del último decenio del siglo XVIII, quien precisamente como promotor de ideas revolucionarias francesas había perdido su empleo como "estensore" de la Gazzetta Universale de Livorno, transfiriéndose en 1790 a la Isla. Si bien continuando la "correspondencia" con la Gazzetta livornesa, Buonarroti asumió la dirección del Giornale patriottico di Corsica ${ }^{14}$, dando vida a una de las primeras tentativas italianas de periodismo de opinión, a los efectos de proporcionar apoyatura a la política de Pasquale Paoli, en el momento en que éste retornaba a la Isla como "héroe de la libertad"15.

\footnotetext{
9 Art. 1, Título X, De la Religión.

$10 \mathrm{El}$ artículo I del Título VII (De la libertad individual y de la de imprenta), prescribe que "nadie podrá ser privado de su libertad y propiedad, si no fuera por decisión de Tribunales previstos por la ley, y en los casos, y según la forma prescritos por dicha ley".

11 Para más meditadas consideraciones al respecto, véase Rovere, op. cit. (n. 4).

12 Así Trampus, op. cit. (n. 3), p. 243.

13 OnNis, R. P.: Filippo Buonarroti e altri studi, Roma, Edizioni di storia e letteratura, 1971, p. 204.

14 El Giornale patriottico della Corsica vio la luz el 3 de abril de 1790, y se conservan sólo 32 números, hasta el 27 de noviembre de dicho año; cfr., SAITTA, A.: "Il discorso preliminare al "Giornale patriottico di Corsica" di F. B.”, Critica storica, V (1966), pp. 589-609.

15 Desde el fascículo inicial, editado el 3 de abril de 1790, Buonarroti recalcaba cómo con sus escritos quería indicar "a los hombres en qué consisten las acciones útiles, y en qué las nocivas" y se asignaba la tarea de instruir a un pueblo ignorante indicándole "el remedio para el mal presente, puesto que aquello que preparaba la libertad de Francia, podría quizás anudar más fuertemente las cadenas, o resultar inútil en Inglaterra". Se hacía necesario pues, según parecer de Buonarroti, someter a examen sobre todo cuál era la condición de un pueblo, y concretar en qué podría consistir su felicidad.
} 
Si bien a la historiografía le resultaba ya familiar la actividad desenvuelta por Filippo Buonarroti ${ }^{16}$, no parece investigada sin embargo la actividad editorial ligada a la presencia inglesa en la Isla, actuada a través de la edición de papeles sueltos y gacetas, redactadas en italiano, y que contemplaba la publicación de noticias estrechamente conectadas con las vicisitudes constitucionales.

Se trata, a mi entender, de una de las formas primigenias de periodismo de matriz e inspiración inglesa, surgidas precisamente en momentos de encrucijada, cuando bajo la égida protectora de Gran Bretaña, se alcanzaba la promulgación de textos constitucionales.

Algunos testimonios relativos a la capacidad inglesa de creación de una opinión pública favorable a su gobierno pueden detectarse ya desde los primeros meses de 1794, en la Gazzetta Universale ${ }^{17}$, una de las más tempranas experiencias periodísticas de la península italiana, en la cual, en esos años, no colaboraba Buonarroti, precisamente por la tendencia anti-francesa asumida por la redacción ${ }^{18}$.

Los lectores de dicha Gazzetta, y especialmente los ciudadanos corsos, llegaban a saber de la actividad desenvuelta por Gran Bretaña para asegurar la pacificación y felicidad de la Isla, por ejemplo, a través de una Relazione dei fatti di Armi accaduti in Corsica dopo la comparsa della Flotta Inglese nel Golfo di S. Fiorenzo fino a tutto il 25 febbraio 1794 (Livorno 9 de Marzo) ${ }^{19}$.

El gacetero, refiriendo el comportamiento de los británicos respecto a la Isla, reiteraba, intentando suscitar en los lectores un efecto benévolo, adjetivos elogiosos de sus intenciones: "[...] Inmediatamente después de tomar esta Torre... los valientes ingleses transportaron allí cañones de gran calibre... Es díficil expresar con cuánto ardor y solicitud los valientes ingleses se abrieron camino entre las ruinas..."

Se subrayaba, así, la colaboración entre los dos pueblos, y respecto al asalto de una posición francesa, escribía:

\footnotetext{
16 Acerca de Buonarroti cabe remitirse a SaItTA, A.: "Buonarroti Filippo", Dizionario Biografico degli Italiani, 15 (1972), pp. 148-161, y a la bibliografía allí citada.

17 Se trata de una de las más tempranas experiencias periodísticas italianas, generada en Foligno, de siempre un centro importante para el desarrollo de la imprenta, no sólo periódica, en Umbria. El periódico surge presumiblemente en 1775, impreso por Pompeo Campana.

18 Desde 1791 Buonarroti interrumpió sus relaciones como colaborador de la Gazzetta Universale y con el redactor Vincenzo Piombi. Se debían las divergencias a la manipulación sufrida por las noticias enviadas por Buonarroti relativas a asuntos de Córcega. Como ejemplo de tal cosa, entre otros muchos posibles, puede citarse una carta del siguiente tenor: "Pisa, 22 de junio de 1791. Veo, a la vista de vuestro papel de ayer, que sois incapaz de decir verdad alguna; dignaos pues a reenviarme la relación verídica del asunto de Bastia que os he enviado. No sé cómo compaginar con vuestra sabida honestidad las mentiras y calumnias que aparecen vertidas en vuestros papeles; si os resulta imposible ser imparcial, al menos guardad silencio. Mandadme aquí, directamente, al Señor Cosimo Mari los papeles que me enviasteis en Bastia. ¿Qué pasa con Gigli? Creedme de veras amigo aff.mo vuestro Buonarroti. P. S. Disculpad mi habitual franqueza. Al Señor Vicenzo Piombi, Redactor de la 'Gazetta Universale'”, Firenze, Segreteria di Stato, anno 1792, prot. 5, n. 8, Straordinari”. La carta aparece publicada en ONNIS, op. cit., pp. 242-243.

19 Véase la Gazzetta Universale, n. 20, martes 11 de marzo de 1794, pp. 158-160.
} 
[...] Se ejecutó esto de noche, lo efectuaron dos columnas, una inglesa, otra de Corsos, que habían de encontrarse en mitad de la posición enemiga, y reconocerse mutuamente con el nombre del Rey Jorge, una parte, y el de Paoli, la otra... ${ }^{20}$.

En un artículo de 8 de julio, se reproducía el discurso pronunciado por el Comisario plenipotenciario Gilbert Elliot acerca de la Constitución recientemente promulgada en la Isla.

Elliot, subrayando el carácter pactado de la unión, y enfatizando la libertad de los corsos, aseguraba que, precisamente para no hacer bascular todo sobre las bondades y virtudes del soberano, "Habéis tenido la precaución de asegurarla con una sabia Constitución" y como prueba de la lealtad de la Corona británica respecto a sus nuevos aliados, recordaba a los isleños que:

Por vuestra parte, ¿que os hacía falta para ser felices? Os lo diré en dos palabras: Libertad en lo interior, Seguridad en el exterior. Vuestra libertad no podrá sufrir alteración alguna en manos de un Rey cuyos ancestros, como se ha probado con una experiencia más que secular, basan la gloria y el esplendor del Trono en la Libertad y felicidad del Pueblo ${ }^{21}$.

Gran Bretaña, sin embargo, no podía conformarse con la publicación de noticias, por muy favorables que resultasen respecto a su política, en una gaceta que no fuese del todo controlable: necesitaba un auténtico órgano impreso que la representase de manera oficial en la Isla. Por tal motivo, y para reforzar todavía más los sentimientos que unían a los corsos con los ingleses, el gobierno anglo-corso prolongaba la intervención en la formación del consenso a través de una nueva publicación, titulada Gazzetta Corsa ${ }^{22}$.

La Gazzetta Corsa era inicialmente un periódico de aparición semanal, publicado cada sábado. Pero tras los primeros seis meses se convirtió en bisemanal, probablemente. El primer número apareció el 9 de enero de 1796 y, como la inmensa mayoría de los periódicos coetáneos, se presentaba en formato a dos columnas, omitía la información relativa a la tipografía, y también omitía la firma de las noticias breves, aunque resulta fácil colegir que los redactores eran corsos. De hecho el gacetero de turno, al referir las vicisitudes estrechamente conectadas con la vida política de la Isla, no se eximía de emitir juicios positivos de valor que manifestaban un sincero

\footnotetext{
20 Ibidem, p. 158.

21 "Este sagrado pacto, que yo recibo de vuestras manos, no es un frío e interesado contrato de dos partes que se encuentran por accidente, cercanas sólo a tenor de las necesidades del momento, o por una política egoista y pasajera. No, este día hermoso es el del cumplimiento de nuestros antiguos deseos. No hacemos hoy sino estrechar nuestras manos. Hace tiempo que nuestros corazones están entrelazados, y nuestra divisa debe ser Amigos, y no por casualidad". Discorso pronunciado por Gilbert Elliot ante la Asamblea General reunida para la aprobación de la Constitución del Reino Anglo-Corso, publicado en la Gazzetta Universale, n. 57, sábado 19 de julio de 1794, pp. 454-455.

22 Tras largas y laboriosas pesquisas, he conseguido hacerme sólo con dos entregas de la Gazzetta Corsa. El primero se conserva en Londres, National Archives, con la signatura PRO- FO 20/9; respecto al segundo, agradezco sinceramente al doctor Alain Venturini, director de los Archives de la Corse-du-Sud, por la amabilidad con la que ha respondido a mis peticiones, proporcionándome una copia del número " $23^{\circ}$ del Sabbato 11 Giugno 1796" de la Gazzetta Corsa.
} 
compromiso all'Isola: “Las Salas estaban decoradas con gusto mediante emblemas y Armas de S. M., junto a las cuales aparecían las de nuestro Reino”, y añadía:

No resulta un espectáculo indiferente para los corazones sensibles ver en esta fiesta Nacional un gran número de aquellos franceses, a los que $\mathrm{S}$. M. ha concedido asilo y protección en esta Ciudad, que unen sus sentimientos de reconocimiento, y de amor hacia los ingleses, y de los Corsos respecto a su Soberano, acompañados de aclamaciones sinceras de la Reina, el Rey, y por la prosperidad de Córcega ${ }^{23}$.

La Gazzetta Corsa, con todo, tenía como propósito fundamental hacer nacer en el lector un afecto sincero respecto a Inglaterra, su grandeza y sus instituciones, subrayando su estabilidad y riqueza ${ }^{24}$ en comparación con Francia, a la que se situaba al borde de una "ruina inminente y universal" 25 , aunque siempre dispuesta a fomentar revueltas en daño de las posesiones inglesas en el Mediterráneo.

En la proclama del 3 de junio de 1796, publicada en la Gazzetta de 11 de junio, se denunciaban, por ejemplo, reuniones clandestinas presumiblemente inducidas por los franceses:

Los primeros movimientos dieron lugar a sospechas relativas a alguna trama combinada por el Republicanismo francés; pero si en cualquier caso un puñado de malintecionados abrigaran propósitos en este sentido, la opinión general lo había sofocado, ya que una Diputación enviada a la Corte de S. E., [...] manifestó [...] la más intensa adherencia al actual gobierno, fidelidad al Soberano, y respeto y amor hacia su Representante ${ }^{26}$.

Y de nuevo se subrayaba la clemencia, benevolencia, y "munificencia de nuestro Soberano" llamando a la "más palmaria, y eficaz colaboración contra [...] los agen-

23 Cfr. Gazzetta Corsa, n. 3, sábado 23 de enero de 1796, p. 9.

24 "Londres, 11 de diciembre. Esta capital está tranquila. La toma del Cabo de Buena Esperanza ha contribuido no poco a tranquilizar a los descontentos. No puede decirse la alegría que tal noticia ha suscitado en el pueblo, que se cree ahora señor de todas las riquezas de Holanda, las de la India como las europeas. Aunque el préstamo de 18 millones de libras esterlinas ha sido satisfecho, muchos capitalistas no encuentran cómo emplear sus capitales, tanta es la afluencia de dinero aquí producida con el actual monopolio del comercio resultante de nuestros éxitos en el mar, y con la ruina de los holandeses... Se muestra creciente el éxito del Sr. Ministro Pitt en sus resoluciones y medidas, que se van adoptando para los asuntos en curso. Los dos Bill que tratan de proporcionar mayor fuerza al gobierno, uno contra las Uniones que pudieran desembocar en la promoción de tumultos, otro para la salvaguarda y preservación de S. M. y del Gobierno, han sido aprobados por mayoría, el primero de 266 votos contra 51, el otro de 226 contra 45...”, ibidem, pp. 9-10.

25 Las noticias relativas a Francia eran del siguiente tenor: "En la Legislatura Francesa, desde hace mucho tiempo ya, no se trata de otra cosa sino de asuntos de Finanzas; de la escasez de numerario, del descrédito absoluto de los Assignates, de la inexistencia de Comercio y de la paralización de la Industria, todo lo cual ha arrojado al Gobierno en una penuria que parece presagiar una inminente ruina universal. Los remedios hasta aquí propuestos y adoptados no hacen sino anunciar de la misma manera el estado deplorable de las Finanzas; el Cuerpo Legiaslativo no ha hasta ahora encontrado otros recursos para satisfacer las apremiantes demandas del Directorio Ejecutivo, que decretar un impuesto forzoso de seiscientos millones, y la venta de los Bosque Nacionales, de los Palacios Reales, de los Bienes de los Príncipes de la Sangre Emigrados, y de todos los otros Emigrados"; ibidem, p. 10.

26 Gazzetta Corsa, n. 23, sábado 11 de junio de 1796, p. 89. 
tes del enemigo" que habían recurrido a "profunda mala fe" con el fin de hacer a los habitantes de Córcega "insensibles ante la actividad benefactora del Rey"27.

Presumiblemente, el experimento editorial de la Gazzetta Corsa terminaba el 8 de octubre de 1796 con el número 56; y pocos días, más tarde, el 19 de octubre de 1796, llegaba a su fín también el Reino Anglo-Corso.

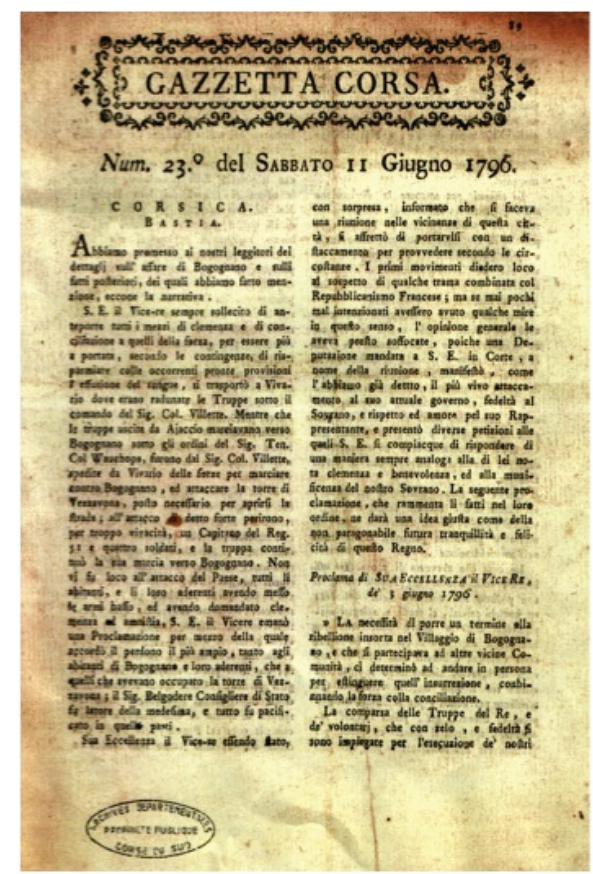

\section{LA EXPERIENCIA CONSTITUCIONAL EN MALTA Y LAS GACETAS DE VITTORIO BARZONI}

Si las vicisitudes del Reyno Anglo-Corso constituían uno de los episodios más fascinantes de la Revolución francesa, hecho posible a partir de la intervención inglesa en la isla, seguramente de superior relevancia, desde una óptica constitucional y de circulación de las ideas, resultaba la ocupación británica de la isla de Malta.

27 Siempre según el texto de la misma proclama, su excelencia el Virrey se remitía a la parte más culta de la población, a aquéllos que "en posesión por fortuna de una educación, y de una situación de notabilidad, tenéis el imperio de lo ejemplar, y de la influencia sobre los Conciudadanos de su entorno, cooperáis unánimemente a ilustrarles y dirigirles hacia el fin consecuente al honor y al interés nacional; las discordias y divisiones, sobre todo en las presentes circunstancias, arrastrarían a vuestra Patria, y a vosotros mismos, a la perdición, de la cual sería imposible sustraerse en los tiempos venideros. Su Majestad, siempre magnánima, generosa y leal en sus promesas, no ahorrará nunca medios a su disposición para proteger a esta Nación; pero esta Nación misma debe estar constantemente decidida a precaverse contra los Enemigos internos que la conmueven, y contra los externos que la amenazan, y empleando su cooperación, según los métodos y las circunstancias que le serán indicados por la legítima autoridad. Homenajes superfluos no corresponden a la necesidad de los tiempos ni a lo que es debido. Al respecto, Su Majestad solicita actuaciones que no pueden verificarse sino mediante la obediencia a su Gobierno". Ibidem, pp. 90-91. 
Ello es así incluso -como subraya Daniela Novarese- si las renovadas demandas constitucionales no alcanzaron a plasmarse en la redacción de textos constitucionales, puesto que la experiencia vivida en la isla bajo control inglés, en esos primeros años del Ochocientos, es de notable importancia para la reconstrucción de "la continuidad y discontinuidad" del proceso de constitucionalización en el área del Mediterráneo ${ }^{28}$.

Liberados en 1800 de la ocupación francesa de la isla, sus habitantes conseguían, bajo protección inglesa, elaborar en 1802 una Dichiarazione dei diritti degli abitanti delle Isole di Malta e Gozo.

A partir de una lectura atenta de tal documento es pòsible singularizar algunos caracteres de ese constitucionalismo identificable como "euro-mediterraneo", donde se fusionaban simultáneamente elementos de matriz francesa, con explícito reenvío a la Déclaration de 1789, con otros como la significativa remisión al rule of law, principio cardinal del sistema de common law.

Era un clima grávido de sugerencias constitucionales el que se respiraba en Malta en esos años iniciales del Ochocientos, tanto que tras la Dichiarazione producida en 1802, el año siguiente contempló la aparición de otro Progetto di Costituzione per l'Isola di Malta e sue dipendenze ${ }^{29}$. Aunque también aquí se permanece el en terreno de la declaración de intenciones, se puede constatar cómo, desde el artículo primero, se hace referencia no sólo a la Constitución, sino también al código civil y al penal, "común y obligatorio tanto para los Caballeros como para el pueblo carente de nota distintiva alguna" ${ }^{30}$, signo tal cosa de un debate que implicaba y acomunaba a gran parte de la opinión pública europea ${ }^{31}$.

A tenor de cuanto viene dicho, sin embargo, causa asombro constatar cómo la constitucionalización de la libertad de imprenta, que había caracterizado y caracterizaba a todas las constituciones de la época, estuviera ausente de ambas propuestas.

Aunque Ricotti detectó precisamente en la Dichiarazione dei diritti degli abitanti delle Isole di Malta e Gozo la reividicación de "prensa libre", me parece que con eso no se rebasa el ámbito de una proclamación de libertad de conciencia y de religión (artículos 7 y 8), y de libertad personal ${ }^{32}$.

Por lo demás, tal ausencia no impedía que la isla se convirtiera, a partir de 1804 y con la llegada de Vittorio Barzoni, en una importante cabeza de puente ideológica,

28 Novarese, op. cit. (n.6), p. 35.

29 Tal proyecto recibe también el nombre de Proyecto Hawkesbury, a tenor del nombre del Ministro de Asuntos Exteriores inglés que había acordado su texto con el embajador en Petersburgo, Sir John Worren. Cfr. RicotтI, op. cit. (n. 5), pp. 481-483.

30 Ibidem, p. 481.

31 Ambos procesos, de constitucionalización y de codificación, se presentan en este tiempo estrechamente interconectados, incluso si, como ha sido ampliamente documentado por Daniela Novarese, en Sicilia por ejemplo la "Carta palermitana" de 1812, representaba el fruto más maduro de esa experiencia, mientras que el diseño codificador, limitado a los proyectos de código penal y de procedimiento civil, no habría de superar la fase de proyecto. Véase al respecto, Novarese, D.: Costituzione e codificazione nella Sicilia dell'Ottocento: il "progetto di Codice Penale" del 1813, Milán, Giuffrè, 2000; Cocchiara, A.: Istituzioni giudiziarie e amministrazione della giustizia nella Sicilia borbonica, Milán, Giuffrè, 2003.

32 En efecto, el artículo 9 establecía que "ningún hombre posee autoridad personal sobre la vida, propiedad y libertad de otro. El poder reside tan sólo en la ley, y la contención y punición pueden ejercitarse exclusivamente en obediencia a la ley". Dichiarazione dei diritti degli abitanti delle Isole di Malta e Gozo, Malta, 15de junio de1802, cita que puede leerse también ahora en RicotTI, op. cit. (n. 3), pp. 479-480. 
mediante el florecimiento de una incisiva y eficaz publicística antifrancesa y antinapoleónica.

La misma presencia inglesa era garantía, probablemente, del reconocimiento de libertades consideradas a esas alturas fundamentales e inviolables, y eso hasta el punto de que quizás no hacía falta al respecto confirmación por escrito.

Efectivamente, Malta devenía así uno de los principales centros propagandísticos ingleses, ejercitando el papel de apoyatura crucial para el "contrabando de mercancías y de ideas".

Inspirador y promotor de esta enérgica pulsión publicística era, coma ya se ha dicho, Vittorio Barzoni, uno de los primeros y más vehementes críticos y opositores italianos de Napoleón, patriota y polemista que, tras su expulsión de Viena, se refugiaba en Malta en los primeros meses de 1804, poniendo en marcha desde allí numerosas gacetas ${ }^{33}$.

En dicho año, en efecto, aparecía su primer periódico, inicialmente titulado L'Argo, y luego Il Cartaginese. Giornale Politico ${ }^{34}$. Esta gaceta asumía la tarea de promover una intensa actividad de propaganda contra la cada vez más agobiante presencia hegemónica francesa en el Continente.

Tras una fase inicial de rampante antijacobinismo, Barzoni alcanzaba la teorización y valoración positiva de un ejemplo constitucional que, en contraposición a abstractos modelos revolucionarios, venía a la postre a identificarse con la constitución inglesa. No era casualidad que en el segundo número del Cartaginese pudiera leerse:

Gran Bretaña no tiene sino que conservar intacta su Constitución, para salir victoriosa en cualquier enfrentamiento. La Magna Carta es el más robusto baluarte defensivo, y la más poderosa máquina ofensiva que los ingleses pueden oponer a sus enemigos ${ }^{35}$.

Este primer experimento editorial terminaba en 1808, pero Vittorio Barzoni publicaba, en ese mismo año el Giornale Politico, un nuevo periódico que, a la vista de las mutaciones que se operaban en los tronos europeos, tenía como meta apoyar la resistencia española contra la invasión por la tropas napoleónicas. Cambiada su denominación, ahora Gazzetta straordinaria, se daría fin a su publicación en octubre de 1810.

El año de 1812 representaba, como es sabido, un año de particular relevancia para la afirmación de los principios constitucionales en el área del Mediterráneo. Como en España y en Sicilia, también los habitantes de Malta, en este momento, suscribían un nuevo Memoriale mediante el cual reivindicaban explícitamente la

restitución de nuestros Antiguos y Sacrosantos Derechos, conculcados por los últimos Maestros de la Orden de San Juan, ya gozados por nosotros durante el bloqueo de

33 Sobre Vittorio Barzoni, cfr., Nuzzo, G.: "Barzoni Vittorio", Dizionario Biografico degli Italiani, 7 (1965), pp. 41-44; RicotTI, op. cit. (n. 3), pp. 245-250; Bozzola, A.: "Un antigiacobino veneto: Vittorio Barzoni”, Archivio Veneto, LXIV-LXV (1959); Kovalevski, M.: La fin d'une Aristocratie, Turín, Bocca, 1901.

34 Esta Gaceta, impresa en Malta, redactada por Vittorio Barzoni, comenzó a publicarse el primero de octubre de 1804, y carecía de periodicidad regular, aunque creo que aparecieron dos fascículos al mes. La colección que poseo se interrumpe el 30 de septiembre de 1805.

35 Il Cartaginese Giornale Politico, n. 2, 10 de octubre de 1804, p. 8. 
La Valetta, estipulados con precisión en el momento de consignar nuestra isla, con fe ilimitada, a los oficiales de S. M.

Rezaba así la Instancia que venía a solicitarse de nuevo en los primeros días de enero de 1812 a Lord Liverpool, barón de Hawkesbury, protagonista de la primera fase constitucional maltesa ${ }^{36}$.

Allí podía leerse, entre otras cosas, la demanda, esta vez manifiesta, de "Prensa libre, pero no licenciosa, en las cosas y situaciones no ofensivas para nuestra Católica Religión". La solicitud de "Imprenta libre" partía de la singular situación en que se encontraba la imprenta en la isla, sujeta a un completo monopolio gubernativo: de hecho, y a tenor de la ley vigente

ningún tráfico o asunto podía ser ejercitado sin previa licencia del Gobierno; ninguna licencia para el ejercicio del tráfico de impresión, y para el uso de una prensa, para cualquier tipo de fin, ha sido nunca concedida. 2. Las prensas en uso en la Isla que careciesen de tal licencia han sido secuestradas por el Gobierno ${ }^{37}$.

Habida cuenta de la condición de la imprenta en la Isla, Vittorio Barzoni debía sentirse bien protegido si en 1812, en un reabierto "clima constituzionale", no dejaba de hacer oir, incluso entonces, la propia voz mediante una nueva publicación, el Giornale di Malta, que se caracterizaba, más si cabe, por la promoción de posiciones británicas en detrimento de las napoleónicas. El primer número aparecía, al precio de dos Tarines, el martes 7 de enero de 1812, editado en las prensas de la Stamperia del Giornale, figurando en el pie de imprenta Sevaglios Sergente, Impresor del Regimiento Siciliano. Este nuevo periódico nacía de la colaboración de Barzoni con Giuseppe Casolani.

En el aviso Al Pubblico, casi un preámbulo a la publicación, el redactor se dirigía a sus lectores señalando explícitamente el carácter necesario del derecho que asistía a todos los hombres en cuanto a conocimiento e información:

En esta época extraordinaria, los hechos generales de Europa interesan a todos los hombres, puesto que una buena parte de ellos está empeñada en sacudirse del cuello el yugo que sufre, y otra parte parte está empeñada en impedir que otro no venga a susti-

36 El Memorial "suscrito por más de significados isleños el 10 de julio de 1811, y enviado a Lord Liverpool el 3 de enero de 1812" elencaba sintéticamente los “antiguos derechos" en posesión del pueblo maltés y ahora reivindicados expresamente. Entre tales derechos, la solicitud de un "Jurado a la manera de Inglaterra", de "Tribunales indipendientes", de "Imprenta libre" y, en fin, de "una constitución, que acomune el espíritu de nuestro antiguo, libre y único legítimo gobierno con el de la Constitución inglesa" eran los elementos más significativos de la influencia del pensamiento constitucional inglés en este ámbito del Mediterráneo. El Memorial aparece ahora reproducido en el apéndice documental de RicOTTI, op. cit. (n. 4, 2005), pp. 490-492.

37 Precisamente en estos años, exactamente en 1810, pudo darse un caso de secuestro de imprenta: "El Sr. Calvert, comerciante británico, residente en Malta, ..., introdujo una imprenta para uso privado. Poco después de la llegada de la imprenta a la isla, recibió una intimación del Gobierno, afirmando que éste no le habría dado permiso para tenerlo, pero que se mostraba dispuesto a comprarlo. La prensa fue consecuentemente consignada al Gobierno, y trasladada a la Imprenta de dicho gobierno, asignándose una indemnización de Sc. 955 a dicho Sr. Calvert", cfr. Rapporti dei commissari sugli affari dell'Isola di Malta, Malta, Per Filippo Izzo e C., 1838, pp. 8-9. 
tuirlo [...] En estos tiempos, Malta está especialmente interesada en las vicisitudes del mundo. Estando afortunadamente esta isla bajo los auspicios del Imperio Británico, se encuentra necesariamente impelida a mantener en todo momento la mirada puesta sobre los acontecimientos terrestres y marítimos que protagonizan las Armas Inglesas; viviendo bajo un Gobierno que ha dado fundamento a su florecimiento, y que protege su libertad, está necesariamente interesada en el mantenimiento de dicho Gobierno; y habiendo, bajo protección de la Bandera Inglesa, ampliado su comercio hasta alcanzar todas las playas del Mediterráneo, siente extrema necesidad de saber qué sucede en todos esos parajes, para agilizar sus expediciones, aumentar sus riquezas, desenvolver con seguridad sus negociaciones. Todos estos motivos de peso dan prueba de lo perentorio que resulta que los Malteses sepan qué es lo que sucede en su entorno. A tal efecto, se ha decidido lanzar un papel periódico ${ }^{38}$.

Con el exilio de Napoleón en la Isla de Elba, Vittorio Barzoni se consideraba satisfecho respecto a su papel como periodista político, de manera que el 20 de octubre de 1813 ponía fin a la publicación del Giornale di Malta ${ }^{39}$ y solicitaba de sir Thomas Maitland el permiso para retornar a Italia, donde moriría el 21 de abril de 1843 . Mediante su actividad periodística ${ }^{40}$ el gacetero de Lonato había rendido un útil servicio a Gran Bretaña, tanto que el gobierno inglés acabaría consignándole una pensión.

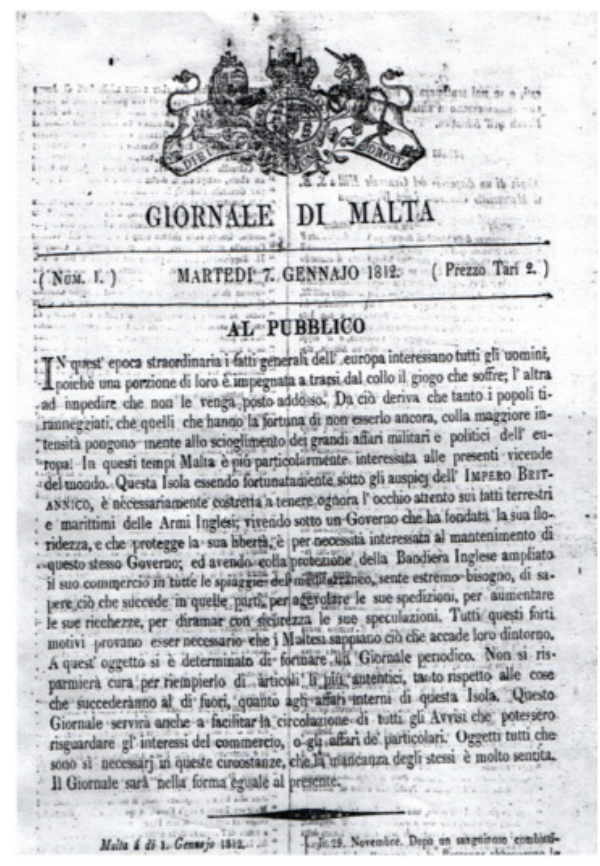

38 "Al pubblico", Giornale di Malta, n. 1, martes 7 de enero de 1812, p. 1.

39 Ocupando su espacio, veía la luz la Gazzetta del Governo di Malta, cuya publicación se finiquitaba presumiblemente en 1815.

40 La obra publicística de Barzoni ha sido objeto de varios estudios, aunque tengo para mí que sin embargo queda espacio para una nueva relectura, precisamente en relación con esta comparación entre modelo constitucional inglés, formación de opinión pública, e impresión de gacetas. 


\section{EI FOGLIO PERIODICO DI SARDEGNA Y LA PRESENCIA INGLESA EN LA ISLA}

Mientras los ejércitos napoleónicos por el momento triunfaban en el Continente, en los confines meridionales de Europa la resistencia al expansionismo francés no era exclusivamente militar, y tendía -bajo protección británica- también a expresarse mediante la formación de una opinión pública atenta y consciente de sus propios derechos. En efecto, mediante periódicos y gacetas que, en número creciente, se imprimían bajo control inglés, se apelaba precisamente al sentimiento nacional y al deseo de libertad de los "italianos", instigándose así la oposición hacia el régimen napoleónico. Es en este contexto donde deben ser comprendidas determinadas experiencias que, en caso contrario, aparecerían excéntricas, como es el caso del patriotismo sardo.

A partir de febrero de 1806, Cerdeña se convertía en sede de la Corte piamontesa, la cual se refugiaba en Cagliari para evitar al ejército napoleónico. Cuando en 1808 Francia decretó el embargo sobre las naves corsas, vetando todo comercio con la isla, Vittorio Emmanuel I, a instancias de Guglielmo Hill, representante britanico en la corte sabauda, que prometió ayuda y financiación, cerró los puertos al comercio francés.

Con la crisis económica alcanzando cotas de extrema gravedad, Cerdeña no permaneció al margen de las tensiones ideales y de la fermentación política que hacia 1812 recorrían Europa entera, donde por lo demás, empezaban a hacerse perceptibles las primeras grietas en el edificio construido por Napoleón. También en Cagliari se empezaba a pensar en la posibilidad de un futuro post-napoleónico. En esa situación de redefinición político-institucional, Inglaterra pasaba a ejercer una influencia notable, no sólo en términos económicos, sino también en el terreno ideológico, sobre todo en medios "sabios e ilustrados". Liberalismo y constitucionalismo eran las armas de lucha conceptual indispensable para hacerse con el consenso de la nobleza, la burguesía, y de los sectores cultivados, y a estos elementos recurrían los ingleses para inducir un vuelco de los sardos hacia posiciones contrarias a Napoleón.

No resultaba casual que el mismo Bentinck, protagonista del momento constitucional siciliano, se desplazara hasta Cagliari a finales de 1811, en busca del rey. La misión del plenipotenciario inglés tenía como finalidad verificar la disponibilidad del gobierno sabaudo a los efectos de una alianza militar con Inglaterra. Las conversaciones progresaron durante varios meses, para a la postre desembocar en nada, sobre todo por la hostilidad de Vittorio Emanuele hacia la idea, avanzada por los ingleses, de una concesión de constitución, como en ese mismo momento era "Real de Cagliari, desde el 28 de enero de 1812 hasta el 28 de julio de 1813, por iniciativa de Adolfo Palmedo, publicista polaco (o quizás de origen italiano) al servicio del gobierno británico.

No era casualidad que, a pesar de que la población sarda atribuyera la ruina económica de la isla a la política del gobierno británico, tanto la guerrilla española, como la Constitución de Cádiz, los acontecimientos sicilianos y la implicación inglesa en la lucha antinapoleónica encontraran el apoyo y el consenso de la bur- 
guesía insular, que encontraba información sobre esos extremos en el Foglio de Palmedo. En el Epitome politico con que se abría el primer número, Adolfo Palmedo ${ }^{41}$ escribía:

Pensamos que quizás no resulte descarado al lector de esta hoja poner bajo sus ojos un rápido esbozo del estado de Europa, y de los asuntos generales en el momento de terminarse el año de 1811, que acaba de expirar. Así, les invitamos a hacer con nosotros un pequeño paseo político, al cual daremos principio razonando desde Inglaterra, (la cual) gobernada por un Príncipe Sabio, y por un Ministerio firme, activo e ilustrado, resulta plenamente victoriosa no sólo sobre el Océano, y sobre todos los mares, sino también en lo que se refiere a la lucha en el Continente, tal como la ha emprendido y mantiene en la Península Ibérica ${ }^{42}$.

Palmedo no dejaba de subrayar, siempre en menoscabo de la política francesa, la situación en que habían recaído los ciudadanos del Reino de Italia, privados de libertades fundamentales, entre las cuales estaba precisamente la libertad de imprenta:

El Virrey, con un decreto dado en Monza el 27 de noviembre, ha prescrito que en cada Departamento del Reino no habrá más que un único periódico en el que se recojan noticias políticas. Todo periódico estará sujeto a la aprobación del Prefecto ${ }^{43}$;

y también las tentativas, fracasadas, puestas en marcha por los franceses para apoderarse de Sicilia:

Parece que el enemigo, disgustado por los esfuerzos inútiles que una y otra vez ha acometido para apoderarse de esta Isla, busca ahora otros medios para conseguir sus fines. Las últimas cartas procedentes de Messina mencionan una conjura puesta al descubierto por la vigilancia del General Inglés Maitland, conjura que intentaba la introducción de un Cuerpo Francés en dicha Plaza, asesinando a todos los ingleses de su guarnición... ${ }^{44}$.

A través del Foglio el redactor, por lo demás, informaba a los lectores sardos también del desenvolvimiento de la guerra antifrancesa en la península ibérica, y sobre todo se hacía cargo de la divulgación de los acontecimientos que habían llevado a las Cortes de Cádiz a la proclamación de una Constitución que, conocida por la Corte de Cagliari, permanecía enterrada entre los papeles de la Secretaría de Estado sabauda, evitada su divulgación por la autoridad. El número 9, de 13 de abril de 1812, por ejemplo, traía la noticia del discurso dirigido por la nueva Regencia a los españoles:

\footnotetext{
41 Sobre Adolfo Palmedo y el Foglio periodico di Sardegna, cfr. Manno, G.: Note sarde e ricordi, Turín, Stamperia Reale, 1868, pp. 252-254.

42 Foglio periodico di Sardegna, n.1, 28 de enero de 1812, p. 1.

43 Ibidem, p. 4.

44 Ibidem.
} 
De ninguna manera puede concluirse que la Regencia, ni por un sólo momento, pudiera dar asentimiento al infausto pensamiento de que el enemigo feroz que nos asalta pueda sobrepasar al heroico pueblo español, que por más de cinco años ha sabido oponerle una gloriosa resistencia. Pudo oirse vuestro grito de independencia y venganza cuando se raptó a vuestros Príncipes, a vuestros próceres, vuestros derechos y vuestras leyes. No teníais entonces ni defensas, ni ejércitos ni jefes, ni gobierno central y respetable.. Y en tal condición, habeis sostenido guerra, mantenido posiciones, y mejorado vuestras instituciones, hasta la reunión de Cortes, el establecimiento de un legítimo gobierno, y formado por medio de vuestros representantes una Constitución que os elevará al grado de prosperidad y grandeza que os mereceis ${ }^{45}$.

Para elaborar la trama apologética de Inglaterra, encontraban espacio en las páginas del Foglio también temas de fuerte impacto político-ideológico como, por ejemplo, la necesidad sostenida por los ingleses de la abolición de la trata de esclavos en los Estados Unidos y Brasil ${ }^{46}$, y en el n. 23, de 20 de agosto, se publicaban los comentarios y boletines de la Grande Armée sobre la desastrosa expedición de Rusia. No comparecían, por otra parte, noticias sobre la situación política local: nada sobre arrestos, condenas, procesos, exiliados y fugados de los conjurados de 1812. Con toda probabilidad, Palmedo había recibido órdenes muy concretas de soslayar cualquier referencia a la situación política interna.

Aparecieron en total 53 números, y en el último Palmedo publicaba una nota en la cual afirmaba que, al haberse publicado la rúbrica Arrivo di Bastimenti sin autorización del gobierno, éste había suprimido la distribución, y por tanto se procedía a reimprimir el número sin dicha rúbrica. En realidad, el redactor del Foglio había incurrido en la culpa de publicar una noticia relativa a la presa hecha en un brich americano por una lancha de una nave inglesa. Y el gobierno, en consecuencia, había ordenado la retirada del fascículo. El enfrentamiento entre Palmedo y el gobierno tuvo como consecuencia última la interrupción definitiva de la publicación.

Aunque faltase en Cerdeña el "momento constituyente", y careciera de desarrollo, en esos años, un auténtico debate constitucional ${ }^{47}$, la gaceta del publicista polaco vino a insertarse en un momento de lucha antinapoleónica, y no debe infravalorarse como componente de tal ámbito, sino por el contrario comprenderse y revaluarse en tal sentido; y por lo demás, también en relación con el clima de restauración creado en Cerdeña por los Saboya, que precedió en quince años al Congreso de Viena.

\footnotetext{
45 Foglio periodico di Sardegna, n. 9, 13 de abril de 1812, p. 33.

46 Foglio periodico di Sardegna, n. 17, 8 de julio de 1812, pp. 67-68 (con continuación en los fascículos 18 y 19$)$.

47 Con especial atención al debate constitucional sardo de finales del siglo XVIII, cfr. MatTONE, A. y SANnA, P.: Settecento sardo e cultura europea: lumi, società, istituzioni nella crisi dell'Antico Regime, Milano, Franco Angeli, 2007, y las referencias citadas en la misma.
} 


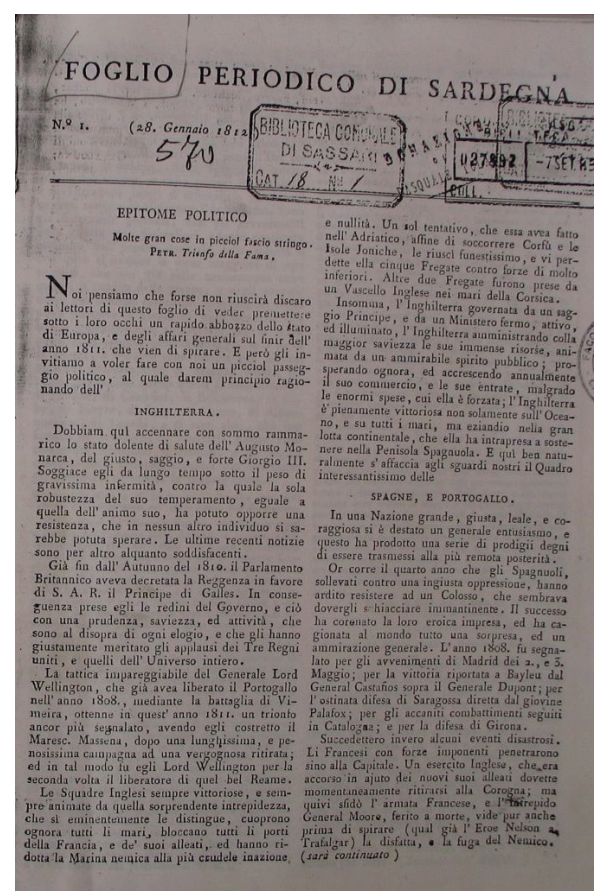

\section{LA PRESENCIA INGLESA EN SICILIA Y LA GAZZETTA BRITANNICA DE MESSINA}

La presencia del ejército inglés en Sicilia convertía en imposible el sueño del general corso de conquistar la isla, pero como apuntaba Francis Gould Leckie: "a Inglaterra le resultaba necesario, para contrarrestar eficazmente a Napoleón y sus ejércitos, intentar la opción de la ofensiva, más que militar, ideológica"48.

Y era ciértamente éste el camino que, sin abandonar otras estrategias de tipo militar o diplomático, comenzaba Inglaterra a recorrer en la Isla desde 1806.

Como ya se ha visto, uno de los mayores centros difusores de noticias antifrancesas era la isla de Malta, que gracias a su posición central en el Mediterráneo, resultaba particularmente idónea para jugar el papel de base en la circulación de las ideas. Mientras en Malta, Vittorio Barzoni, mediante sus gacetas, creaba consenso en torno al gobierno inglés, y se hacía portavoz de demandas constitucionales, también Sicilia se preparaba, bajo la influencia británica, para aprobar hacia un intenso momento constitucional ${ }^{49}$.

\footnotetext{
48 LeCKIE, F. G.: State of the foreign affairs of Great Britain for the year 1809, Londres, Chapel, 1809, p. 10.

49 Entre los ensayos de mayor interés para el asunto de la difusión de las ideas constitucionales europeas, se pueden consultar: Bianco, V. G.: La Sicilia durante l'occupazione inglese. 1806-15, Palermo, ed. Alberto Reber, 1902; Giarrizzo, G.: “1812: Sicilia inglese?”, op. cit. (n. 3), pp. 59-70; Sciacca, E.: Riflessi del Costituzionalismo europeo in Sicilia (1812-1815), Catania, Bonanno, 1966; así como la amplia bibliografía
} 
A decir verdad, la admiración que Gran Bretaña suscitaba en la opinión pública siciliana en los años iniciales del siglo XIX enraiza en la difusión que la cultura inglesa había tenido en la Isla y en general en toda el área mediterránea a partir de la segunda mitad del Setecientos, así como en el interés con que los intelectuales sicilianos contemplaban las instituciones de Gran Bretaña que convertían a los ingleses en "hombres fuertes, magnánimos, independientes y dominadores de las cuatro partes del globo" 50 .

En tal tesitura, Messina, puerta de Sicilia, asumía una importante relevancia estratégico-militar que, especialmente durante la fase del "bloqueo continental", tenía como consecuencia la llegada de más de 7.500 militares ingleses en apoyo de las tropas borbónicas. Simultáneamente llegaban con los anteriores numerosos comerciantes, confirmando así el papel central que las islas del Mediterráneo desempeñaban respecto a los intereses comerciales ingleses ${ }^{51}$.

Tal situación hacía posible que un joven tipógrafo mesinés atrajera la atención de los ingleses que estaban en la ciudad: se trataba de Giovanni Del Nobolo, que emprendiendo la publicación el 5 de julio de 1806 de Notizie Officiali dell'Armata Britannica in Calabria, y autonominándose "Impresor Británico", asumía la tarea de promover una campaña de información y propaganda a favor de Gran Bretaña. Los ingleses parecían caracterizados en ese papel como liberadores de la opresión francesa.

citada en Romano, A.: "Prefazione", en Romano, A. (ed.), Costituzione del Regno di Sicilia, VII ed., Palermo 1813 (facs.), Messina, presso l'Accademia, 1996), pp. XXV-XXXI; Pelleriti, E.: 1812-1848. La Sicilia fra due costituzioni, Milán, Giuffrè, 2000; Romano, A.: "La costituzione siciliana del 1812 e il modello inglese", Atti della Accademia Peloritana dei Pericolanti, classe di Scienze giuridiche, economiche e politiche, LXX (2001), pp. 31-53.

50 Como testimonio de este interés hacia la cultura inglesa cabe traer a colación la relación directa mantenida entre el filósofo de Modica Campailla con Berkeley; del historiador Cubani con Hoyvon, Wodvard, Scherard, Pitton; del economista Balsamo con Young, etc. De la misma manera que fueron miembros de la Academia londinense el Príncipe de Biscari, Caruso, el Paternò de San Giuliano. Por otra parte, no eran escasos los viajeros ingleses que visitaban la Isla en esos precisos años; Brydone, en su viaje a Sicilia de 1770, manifestaba resultar favorablemente sorprendido por la facilidad con que individuos de la alta sociedad conversaban con él en inglés, hasta el punto de escribir en su diario de viaje: "Nos sorprendimos, al llegar a Palermo, al encontrar allí nobles que hablaban inglés, y nos sorprendimos en grado mayor aún cuando esos mismos nobles dieron muestras de conocer perfectamente a algunos de nuestros mejores poetas y de nuestros filósofos. Localizamos, en idioma original, en determinadas bibliotecas, las mejores ediciones de Milton, Shakespeare, Dryden, Pope, Bacon, Bolingbroke. Nuestra lengua ha llegado a estar tan de moda que se la considera componente esencial de una buena educación. El Virrey y el Márqués de Fogliani, hombre de alto mérito, han estudiado detenidamente alguno de nuestros autores, promoviendo grandemente el progreso de este conocimiento en el Reino"; cfr. De MAtTEI, R.: Il pensiero politico siciliano fra il sette e l'ottocento, Catania, Tip. Crescenzio Galatola, 1927, p. 48-49 e 50-51.

51 Se ha interesado también en esta problemática CHIARA, L.: Messina nell'Ottocento: famiglie, patrimoni, attività, Messina, Edizioni Dr. Antonino Sfameni, 2002, pp. 19-23. Entre 1807 y 1812, Sicilia absorbía por sí sola el $80 \%$ de las exportaciones provenientes de Inglaterra en la península, y proporcionaba a su vez el $66 \%$ de las importaciones del área italiana; cfr. D’Angelo, M.: Mercanti inglesi in Sicilia, 1806-1815: rapporti commerciali tra Sicilia e Gran Bretagna nel periodo del blocco continentale, Milán, Giuffrè, 1988. 
La tipografía de los hermanos Del Nobolo asentaba, precisamente en esos años, su fortuna a través de una serie de publicaciones atentas a las vicisitudes revolucionarias francesas y a las primeras tentativas napoleónicas ${ }^{52}$.

Parece cierto que la prensa periódica de la ciudad atendía el consumo de una burguesía acomodada que, lejos del mundo de intrigas de la Corte palermitana, se interesaba sobre todo por movimientos de capital y de fuerza de trabajo, y no podía resultarle ajena cuanto sucediera en el continente. Por tal motivo, tras una serie de diversas publicaciones, y contando con la seguridad del apoyo inglés, Giovanni Del Nobolo iniciaba, desde 1808 y hasta 1814, la publicación de la Gazzetta Britannica, periódico bisemanal que acudía puntualmente a la cita cada miércoles y cada sábado ${ }^{\mathbf{5 3}}$.

Esta gaceta era la expresión de la política antinapoleónica y de la tentativa inglesa de crear una circulacion de ideas favorable y una "opinión pública" en apoyo de la campaña militar británica en el Mediterráneo, buscando contrarrestar el proselitismo que los usurpadores franceses promovían desde la cercana Calabria mediante proclamas dirigidas a los sicilianos ${ }^{54}$.

No resultaba casual que la Gazzetta Britannica de Messina, desde la fecha de su nacimiento, 2 de marzo de 1808, luciese en la cabecera el escudo inglés que, signifi-

52 Giovanni y Giuseppe del Nobolo habrían desenvuelto su actividad de impresores de manera ininterrumpida durante un prolongado período, marcando con ello, por lo demás, la trayectoria de formación de la opinión pública en la ciudad del Estrecho, y pasando de la publicación de gacetas legitimistas a la edición de periódicos constitucionales. Giuseppe inició su actividad en 1784, concluyéndola en 1820; Giovanni, a su vez, emprendía su actividad de publicación en 1793, manteniéndola hasta su fallecimiento. La tradición tipográfica de los Nobolo fue proseguida por la viuda de Giovanni y por el hijo de Giuseppe, Michelangelo, activo como tipógrafo hasta 1869. El primer papel impreso por el taller de Giovanni del Nobolo, fue el Compendio delle notizie più recenti, editado en Messina en 1793 al cuidado de don Antonino Pantò, una colectánea de noticias poco original, que seguía fielmente el modelo de la Gazzetta Universale toscana. Para información al respecto, se reenvía a DE SALVO, P.: "Editori e fogli periodici nella Sicilia fra Sette e Ottocento: il caso di Messina”, en Brocar: Cuadernos de Investigación Histórica, 34 (2010), pp. 33-48.

53 La colección completa de este periódico siciliano (faltando sólo los primeros ocho fascículos de 1808 y los fascículos 10 y 25 del 1812), es ahora consultable en la versión on-line al cuidado de quien esto escribe, en el sitio electrónico de la Biblioteca de la Assemblea Regionale Siciliana en la siguiente dirección abierta: http://www.ars.sicilia.it/biblioteca/gazzetta/gazzetta.jsp

54 La redación daba curso al primer fascículo con el siguiente programa: "Mientras grandes acontecimientos causan la sorpresa del mundo, y han proporcionado materia para enriquecer con volúmenes enteros la historia de nuestros tiempos, un inoportuno silencio ha sobrevenido, así como la total supresión de los papeles públicos. Es consecuencia de esto que algunos, caprichosos o turbios, divulgan noticias o alteradas o enteramente falsas, sostenidas a menudo por papeles franceses o italianos, que son arteramente elaborados para sostén o legitimación de los usurpadores corsos. Son estos los motivos que han hecho que se diera a la luz la presente Gazetta, la cual se limitará a dar noticia de los hechos, al mismo tiempo haciendo conocer con claridad las miras, designios y maniobras ocultas de aquellos que, creyéndose por encima de todo derecho, han ultrajado la amistad, buena fe y lealtad de Reyes y Naciones. Se proporcionará siempre una fecha de Messina para dar cuenta de las noticias que llegan por vía marítima, y se entresacará de los papeles extranjeros aquello que sea de mayor importancia y más digno del conocimiento del público", en Gazzetta Britannica, n. 1, 2 de marzo de 1808, Messina. El texto completo del programa aparece citado por ARENAPRIMO, G.: La stampa periodica a Messina dal 1675 al 1860, Saggio storico bibliografico, Messina, Tipografia D'Amico, 1893, p. 47, teniendo en cuenta que, hasta ahora, no he conseguido encontrar en ninguna de las bibliotecas, nacionales o internacionales, por mí consultadas, los primeros ocho fascículos de la publicación. Por el contrario, me complace recordar aquí la disponibilidad de los bibliotecarios, fotógrafos y demás personal de dichas bibliotecas, en las cuales he desarrollado mi investigación, que me han permitido alcanzar el resultado de una recomposición sustancial de la publicación en su totalidad. 
cativamente se reproducía también en el Giornale di Malta del cual se ha hecho mención anteriormente, y que sucesivamente habrá de singularizar a la Gazzetta Jonia.

La coyuntura que favorecía la publicación de un auténtico periódico político, con periodicidad bisemanal, amplio espacio dedicado a las noticias italianas y exteriores, y una orientación crítica muy precisa, se determinaban a tenor de la verificación de una situación especialmente delicada en la ciudad del Estrecho. De hecho, se insinuaban entre las filas de la burguesía urbana posiciones ideológicas filofrancesas, y en ambas orillas del Estrecho se asistía a un cierto "contrabando" de ideas y acuerdos que causaban preocupación al general Stuart, comandante en jefe del ejército británico en Sicilia.

Con tan novedosa gaceta, mediante una auténtica y eficaz "guerra psicológica" los ingleses daban la réplica al fermento soterrado que los agentes franceses promovían, introduciendo panfletos, avisos y proclamas desde la otra orilla, bloqueando así la difusión de corrientes revolucionarias en la sociedad messinense.

La tipografía de Del Nobolo se convertía también en lugar de encuentro y reconocimiento para cuantos, implicados políticamente, vivían de manera entusiasta esos años caracterizados por la ideología liberal inglesa. No era casualidad, de hecho, que en los aledaños del taller se pudieran adquirir periódicos provenientes de Malta ${ }^{56}$ así como la Cronica di Sicilia y el Giornale Costituzionale ${ }^{57}$ editados en Palermo.

Así pues, si la prensa periódica parecía languidecer en aquellos primeros años del siglo XIX, la situación parecía cambiar drásticamente a tenor de las experiencias constitucionales de 1812, momento crucial a la hora de "la apertura de nuestra conciencia política hacia nuevas aspiraciones de libertad", lo cual desembocaba en el florecimiento de numerosas cabeceras constitucionales ${ }^{58}$.

La redacción de la Gazzetta Britannica, atenta a cuanto sucedía en Palermo, y a subrayar la importancia de la presencia inglesa en la isla, comenzaba la publicación de las noticias relativas a los trabajos parlamentarios con el fascículo número $42 \mathrm{de}$ 1812, donde podía leerse: "Comenzaron los tres brazos el gran asunto, adoptando

55 La referencia a la psycological warfare puede leerse en SpinI, G.: "A proposito di "circolazione delle idee" nel Risorgimento: La "Gazzetta Britannica" di Messina", Miscellanea in onore di Roberto Cessi, vol. III, Roma, Edizioni di storia e letteratura, 1958, pp. 17-34.

56 En la Gazzetta Britannica se proporcionaba noticia de la publicación de los periódicos malteses. En el espacio dedicado a los Avvisi puede, en efecto, leerse: "La suscripción del Giornale di Malta es de 40 tarí malteses (16 tarí de Sicilia) cada seis meses; pagaderos anticipadamente. Cuando lleguen a publicarse dos numeros semanales, lo cual se hará lo más pronto posible, la suscripción se doblará. Las suscripciones se recibirán, por cuenta del Editor de dicho Giornale, en Messina, en la Imprenta del Ejército Británico". Se reproducían también los artículos y las proclamas emitidas por Barzoni para intentar atraer la atención de sus lectores precisamente sobre el experimento constitucional siciliano.

57 "En mi establecimiento se reciben las Suscripciones de algunos folletos que se imprimen en Palermo, a saber: un Giornale Costituzionale que se imprime una vez al mes en la Imprenta de Francesco Abbate, y se paga anticipadamente, doce tarí por cada cuatro meses; la Cronica di Sicilia, que saldrá de las prensas de Gio: Battista Giordano dos veces por semana, pagándose anticipadamente, doce tarí por cada tres meses", "Avvisi", Gazzetta Britannica, 72, 8 de septiembre de 1813, p. 4.

58 Mirabella, T.: "Il giornalismo siciliano dell'Otto-Novecento", en Romeo, R. (dir.): Storia della Sicilia, Palermo, Società Editrice Storia di Napoli e della Sicilia, p. 300. 
como basamento para la nueva Constitución de Sicilia la incomparable Constitución Británica" 59 .

Con la Carta de 1812 Sicilia se convertía, en efecto, en protagonista de aquel proceso de constitucionalización que, con el paso del Setecientos al Ochocientos, hemos visto difundirse por Europa, acabando por interesarla en su conjunto. Hace falta, sin embargo, enfatizar cómo ya a poco de la aprobación parlamentaria de la Constitución ( 7 de noviembre de 1812), y antes de su promulgación (25 de mayo de 1813$)^{60}$, mientras se enconaba el encuentro entre realistas-conservadores y constitucionalesliberales, se comenzó a hablar explícitamente de revisión constitucional. El mismo Balsamo, en sus Riflessioni, ponía en evidencia que: "La nueva Constitución de Sicilia, o por decirlo mejor, el esbozo de la misma, debe mantenerse intacta en cuanto a sus principios, pero en alguna de sus partes debe adaptarse a las observancias, costumbres y usos actuales de la Nación" ${ }^{61}$.

La situación no parecía mejorar con la elección del nuevo parlamento, paralizado por la contraposición violenta entre los partidarios de los democraticos, los costituzionalistas y los legittimistas.

Probablemente con la intención de espolear al parlamento, intentando que lograse en un tiempo corto la redacción del nuevo texto constitucional, se publicaron en la Gazzetta Britannica, con todo lujo de detalles, los actos de festejo con ocasión de la promulgación de la Constitución de Cádiz, el 19 de marzo de $1812^{62}$ y, algunos fascículos más tarde, se proporcionaba la noticia de la publicación solemne en Palermo, en la Iglesia de Monserrato, aledaños del Castello, de la Carta gaditana, jurada por "todos los Españoles, y Españolas, y empleados al servicio de España"63.

En tal contexto de promoción de ideas constitucionales, no es de extrañar que del Nobolo se consagrase definitivamente como tipógrafo "constitucional" gracias a la publicación en italiano de la Costituzione politica della Monarchia spagnola. Es sabido, en efecto, cómo el debate constituyente español despertó particular atención en el seno de la activa burguesía messinense, que lo seguía a través de las crónicas reproducidas en la Gazzetta Britannica. No resultaba casualidad que la constitución gaditana viniese editada precisamente en Messina, en la parte oriental de la Isla, baluarte de los sectores liberal-burgueses, y puede presumirse (es la hipótesis de Romano) que:

59 Gazzetta Britannica, n. 42, 25 de julio de 1812, p. 1.

60 La Constitución del Reino de Sicilia, en su redacción final, aparecía compuesta por las Basi, por un "cuerpo" articulado en tres Títulos (poder legislativo, poder ejecutivo, poder judicial) y por diversos decretos relativos a materias específicas. El texto expresaba claramente la afirmación de las instancias baroniales tendentes a contener, en la medida de lo posible, las prerrogativas regias y la participación de las clases medias en la vida política del país. Con todo, era posible percibir en su texto elementos típicos del modelo inglés, como por ejemplo la estructura de la Asamblea legislativa, subdividida en dos Cámaras, la de los Pares y la Demanial, la adopción del instituto del jurado y del principio de habeas corpus, así como la constitucionalización de garantías y libertades individuales.

61 La citación la trae Romano, A.: "Cadice come modello costituzionale per 1'Europa liberale e antinapoleonica. Nota introduttiva”, en Romano, A. (ed.), Costituzione politica della Monarchia spagnola, reimpresión Soveria Mannelli, Rubbettino, 2000, p. LXXIV.

62 Gazzetta Britannica, n. 27, 3 de junio de 1812, , pp. 1-3.

63 Gazzetta Britannica, n. 45, 5 de agosto 1812, p. 2. 
el medio de obtención de un ejemplar a partir del cual efectuar la traducción lo proporcionase uno de tantos barcos de guerra ingleses que conectaban Sicilia con España, también porque el mismo Bentinck en ese momento (mayo de 1813) se había trasladado a España, al mando del contingente anglo-siculo en Cataluña ${ }^{64}$.

El episodio cobra el aspecto de una confirmación ulterior de la guerra de propaganda promovida por los ingleses contra Francia, a la que, como he procurado demostrar, se intentaba combatir, más allá del aspecto militar, "ideológicamente", en el terreno de los modelos institucionales.

En el Avviso correspondiente a la publicación de la Constitución de Cádiz, y dirigiéndose directamente a sus lectores, Giovanni del Nobolo enfatizaba:

Hemos querido presentar al Público la traducción en Idioma Italiano de la Constitución Política de la Monarquía de España, promulgada en Cádiz el día 19 de marzo del pasado año de 1812, y en Palermo en la Iglesia de Monserrato el 26 de julio, adjuntando para su mejor inteligencia los tres preliminares que se encuentran en las partes respectivas del Proyecto de Constitución presentado a las Cortes por la Comisión, y el reglamento que las mismas han prescrito a la Regencia, a fin de que se haga accesible a quienes desconocen la lengua, y se evite así el peligro de su alteración artificiosa por parte de aquéllos que quisieran hacerla odiosa ${ }^{65}$.

De acuerdo también en esto con Romano, puede resaltarse cómo de ninguna manera resulta casual la decisión de publicar también el Discurso Preliminar, conceptuado por su editor de segura utilidad, habida cuenta de su valor político-exegético, puesto que "dicha traducción intentaba dar a conocer los contenidos efectivos de la Carta gaditana, frente a las críticas de los enemigos de toda Constitución" 66 .

En tal contexto, una particular relevancia suponía para Sicilia el "decreto constitucional" mediante el que se sancionaba la supresión de la censura y la proclamación de la libertad de imprenta, según cuyos términos:

"Todos los cuerpos y personas particulares, de cualquier condición y estado que sean, tienen libertad de escribir, imprimir y publicar sus ideas políticas sin necesidad de licencia, revisión o aprobación alguna anteriores a la publicación, bajo las restricciones y responsabilidades que se expresarán en el presente decreto" ${ }^{97}$.

Dicha providencia intentaba favorecer el surgimiento de periódicos "constitucionalistas", y más genéricamente, "politico-culturales". Como escribía Carlo Capra,

una decena de cabeceras surgieron en pocos años, en Palermo y otras ciudades principales, y notable resultó la viveza del debate así abierto en sus páginas entre las

64 Romano (ed.), op. cit. (n. 53), p. XVII-LXXXVI, en particular p. LXXIII.

65 Ibidem, p. 3.

66 Ibidem, p. LXXV.

67 Cfr. Romano (ed.), op. cit. (nota 43), p. 81. Nótese que la traducción que se proporciona es la transcripción literal del texto español del decreto, su Artículo 1, Colección de Decretos y Ordenes de las Cortes de Cádiz, ed. facsimilar, Madrid, Cortes Generales, 2 vols., 1987, ps. 14-17, en concreto p. 14. 
diversas corrientes políticas comparecientes, de los constitucionalistas moderados a los reaccionarios intransigentes y al naciente partido democrático ${ }^{68}$.

El itinerario que había desembocado en la aprobación del decreto de libertad de imprenta había sido complejo y, no obstante el encuentro de pareceres, se había logrado su confirmación, de manera que por primera vez los sicilianos habrían conocido la posibilidad de imprimir y difundir las propias ideas sin necesidad de recurrir al control preventivo.

Incluso si, como no dejara de apuntar Evola, "la libertad de imprenta es una conquista de las revoluciones, y no resulta fácil establecer si, concedida a pueblos no educados en su ejercicio, ha sido más beneficiosa que perniciosa" ${ }^{69}$.

En un momento de visiones políticas contrastadas, como era el de los meses sucesivos a la proclamación de la Constitución, la libertad de imprenta abrió el camino al surgimiento de folletos polémicos, canciones, sátiras y poesías dirigidas hacia quienes ejercitaban el poder.

La demostración más resonante de tal cosa se tuvo en la inmediatez misma de la promulgación de la Carta siciliana, cuando en el "nuevo" Parlamento, elegido según el dictado constitucional, las fracturas internas se intensificaron, encontrando eco y presencia en el periódico Cronica di Sicilia editado en Palermo.

Tomando como referencia la denominación de la cabecera, pasaron a ser llamados "Cronici" los partidarios de los ingleses, y motejados de "Anticronici" sus adversarios.

La dificultad a la hora de concretar extensión y límites de tal libertad, que aunque declarada constitucionalmente no acababa de encontrar una tutela eficaz a los efectos de su aplicación, habida cuenta de la carencia de certeza jurídica mediante codificación $^{70}$, resulta también testimoniada por el divergente itinerario procesal aplicado a los numerosos procesos por delitos de imprenta y "libelo notorio" que a menudo se transformaban en disputa política ${ }^{71}$.

Expresión del aludido clima resultaban los ataques a la manifestación libre del pensamiento, ataques a los que no se sustraían incluso exponentes de los partidos representados en la Cámara de los Comunes.

Se asistía así a un auténtico duelo entre los diputados de la mayoría de gobierno y los de la oposición, duelo que empujaba a unos y a otros, no sólo a la "barra" de la Cámara, sino a lo que era peor, la cárcel, en ausencia de normativa cierta a la cual apelar, o interpretación unívoca y coerente de la ley ${ }^{72}$.

68 CAPra, C.: "Il giornalismo nell'età rivoluzionaria e napoleonica", en CAPra, C., CASTronOvo, V. y Ricuperati, G.: La stampa italiana dal '500 all'800, Bari-Roma, Laterza, 1986, p. 529.

69 Evola, N. D.: La libertà di stampa in Sicilia (1812, 1820, 1848), Roma, Società Anonima Tipografica Castaldi, 1941, p. 1.

70 Vid. Novarese, op. cit. (n. 28).

71 Sobre este punto me permito remitir a DE SALvo, P.: "Sarà delitto il pubblicare scritti di qualunque sorta...che contengano libelli infamatori". Un processo per violazione della libertà di stampa nella Sicilia costituzionale (1810-1815)", Acta Histriae, 19 (2011), 3, pp. 505-522.

72 Véase la alegación redactada por Filippo Foderà en defensa del joven Marqués Merlo, FoDERÀ, F.: Ricorso del Marchesino D. Giuseppe Merlo all'Alta Corte del Parlamento contro la Gran Corte Criminale, Palermo, per le stampe di Li Pomi, 1815. 


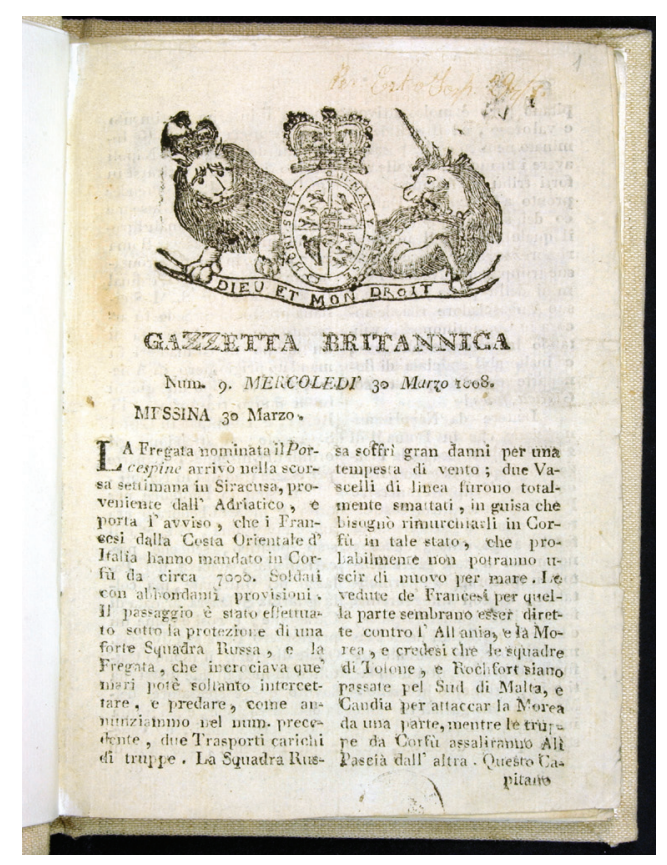

\section{PARA CERRAR EL CÍRCULO: BREVES NOTAS SOBRE LA GAZZETTA JONIA Y LA CONSTITUCIÓN DE LAS ISLAS JONIAS}

Para concluir este recorrido (que se ha desarrollado siguiendo un trazado ideal que tuviera en cuenta el papel desempeñado por la constitucionalización de la libertad de imprenta y la circulación de ideas en las principales islas del Mediterráneo), habremos de ocuparnos de la última experiencia inglesa siginificativa, realizada en el Mar Jonio a partir de 1815.

Se hace necesario aquí recordar, brevemente, que las Islas Jonias fueron desde ya hacía largo tiempo objeto de atención por parte de inglaterra. Como es sabido, antes del estallido de la Revolución Francesa este archipiélago formaba parte de la República de Venecia, y con la disolución de ésta, en 1797, por efecto del Tratado de Campoformio ${ }^{73}$, llegó a ser controlado por Francia.

Una primera tentativa de inserción militar en el Mar Jonio por parte del gobierno inglés se frustró, entre 1798 y 1799, por una expedición conjunta ruso-turca, la cual tras el asedio y captura de la capital Corfú en 1800, ponía fin definitivamente al dominio francés en las Islas Jonias. Así, apoyadas por las tropas inglesas, las fuerzas ocupantes fundaban la República de las Siete Islas Unidas, que sobrevivió hasta 1807. Como enfatiza Ricotti,

73 El Tratado de Campoformio había sido estipulado el 17 de octubre de 1797 entre la Francia napoleónica y Austria. Francia obtenía de Francia Bélgica y Lombardía, y a su vez cedía a la potencia austriaca el Véneto, Istria y Dalmacia, dando por finalizada la independencia de la República Véneta. 
la colaboración entre rusos y turcos habría inaugurado en las Islas Jonias, con el nacimiento de la así llamada "República de las Siete Islas", un importante ciclo de experiencias políticas e institucionales destinado a discurrir entre crisis, revoluciones y reformas hasta resultar en la Restauración, concluyéndose definitivamente con la anexión del archipiélago al Reino de Grecia en $1864^{74}$.

Entre 1807 y 1814 el archipiélago jonio era teatro de enfrentamiento militares y diplomáticos entre Francia e Inglaterra. De nuevo anexionado por Francia en 1807, y encuadrado en el conjunto de las "provincias ilíricas", se sustrajpo de nuevo al dominio napoleonico a partir de 1809. Precisamente en esos años Gran Bretaña ponía en marcha una campaña de conquista de las diversas islas que se concluiría con la caída de Corfú en 1814. A la postre, el Congreso de Viena decidiría poner las Islas Jonias bajo la protección exclusiva del Reino Unido ${ }^{75}$.

La presencia inglesa en el archipiélago de las Islas Jonias se concretaba, entonces, definitivamente a partir de 1814, y no resulta casual que, precisamente en este año, se diese a la imprenta la Gazzetta Jonia, caracterizada, como ya se ha apuntado más arriba, por el escudo inglés impreso significativamente en su frontispicio. Se trataba de una publicación periódica semanal, de aparición regular los sábados, editada en Corfú, a partir del 2 de julio de 1814, en la "Imprenta del Gobierno".

En los primeros números de esta Gazzetta se encuentran elocuentes proclamas de las naciones finalmente liberadas del yugo napoleónico, en defensa de la recién reconquistada libertad, mientras parecía del todo natural la publicación de noticias sobre la generalmente reconocida locura del general corso, extractadas a partir de opúsculos y escritos que, ya no sujetos a censura alguna, expresaban libremente la oposición al Emperador:

Para empezar, se trata del sistema continental de Bonaparte, sistema propio de un loco o un niño, que no era el fin real de la guerra, sino más bien mero pretexto, queriendo convertirse en soberano del mundo, no hablándose de otra cosa que de la libertad de los mares. ¿Hizo lo conveniente para el establecimiento de este sistema insensato? Mediante dos grandes errores que han hecho embarrancar (sic) sus proyectos en España y en Rusia, ¿no corrió el riesgo de cerrar los puertos del Mediterráneo y del Báltico? ¿No entregó todas las colonias del mundo a los ingleses? ¿No les ha abierto el Perú, Méjico, Brasil, a un tráfico más considerable que el que quería erradicar en Europa? La cosa es cierta, ha enriquecido mediante la guerra al mismo pueblo que quería llevar a la ruina ${ }^{76}$.

Certeramente, como demostración de hasta qué punto resultaba intenso el compromiso garante de las libertades constitucionalmente reconocidas, se publicaba el discurso pronunciado por Luis XVIII el 4 de junio en el Palacio del“Cuerpo Legislativo” con

\footnotetext{
74 RicotTi, op. cit. (n. 4, 2005), pp. 320-321.

75 Sobre las vicisitudes histórico - institucionales del archipiélago de las Islas Jonias, puede verse RicOTTI, op. cit. (n. 4, 2005), pp. 319-425.

76 Se trata de un extracto de un opúsculo publicado por François René De Chateaubriand, y reproducido parcialmente en la Gazzetta Jonia, n. 2, 9 de julio de 1814, p. 4.
} 
ocasión de la promulgación de la nueva Carta constitucional ${ }^{77}$, y se daba además noticia procedente de Madrid donde, en plena Restauración,

el Pueblo se ha declarado a favor del Rey Fernando. Los miembros principales de las Cortes han sido arrestados, o se han dado a la fuga [...] Las tropas del Rey están a punto de entrar en Madrid. El Rey ha emitido una proclama en la cual se exhorta a todos los ciudadanos a mantener la paz, y al olvido de ofensas y agravios recíprocos. Para beneficiar su esperanza, añade la promesa de otorgación de una Carta constitucional ajustada a las necesidades de los Pueblos Españoles de ambos hemisferios, y atenida a las luces de Europa, la situación y las circunstancias generales en que nos encontramos ${ }^{78}$.

El interés manifestado por la redacción del semanario respecto a la promulgación de nuevas cartas constitucionales anticipaba de hecho la voluntad del gobierno inglés de proporcionar una nueva constitución para las Islas Jonias, adaptada a la nueva realidad compareciente tras el Congreso de Viena. En 1815 se constituían los Estados Unidos de las Islas Jonias, a tenor de las estipulaciones del Tratado de París, firmado por Rusia e Inglaterra, que establecía: "Este Estado será puesto bajo la inmediata y exclusiva Protección de Su Majestad el Rey del Reino Unido de Gran Bretaña e Irlanda, de sus Herederos y Sucesores..." (art. II), y

Con el fin de proporcionar atenta ejecución a las estipulaciones mencionadas en los artículos anteriores, y para basar la reorganización política de los Estados Jonios sobre la organización actualmente vigente, el Lord Alto Comisario de la Potencia Protectora regulará la forma de Convocatoria de una Asamblea Legislativa, de la cual guiará los pasos para preparar una nueva Carta Constitucional para los Estados Unidos, cuya ratificación será solicitada a Su Majestad el Rey del Reino Unido de Gran Bretaña y de Irlanda (art. IV) ${ }^{79}$.

La tarea de elaboración de la nueva Constitución, contradiciendo las expectativas de los habitantes de las Islas Jonias, y los presupuestos mismos del Tratado de París, se dilataban más allá de un bienio. El gobierno londinense, a través de su Secretario de Estado, Sir Bunbury, dictaba algunos de los puntos fundamentales a los que debía atenerse el nuevo texto, y el alto Comisario Thomas Maitland, al cual ha de reconocerse un papel decisivo en la composición del texto, les daba acomodo completo. Todo apuntaba a que en esta ocasión el gabinete inglés buscaba evitar la repetición de disfunciones e inconvenientes con los que había debido enfrentarse en las precedentes experiencias de Córcega y Sicilia. El texto resultante estaba atravesado por un fuerte talante paternalista. Si bien comparecía una Asamblea Legislativa (de mero apoyo al Ejecutivo) en realidad el principio de separación de poderes resultaba fuertemente puesto en cuestión a favor de un Senado fuerte y autorizado, titular del poder ejecutivo, presidido por lo demás por el Lord Alto Comisario. Inglaterra, entonces, cambiaba de estrategia, renunciaba tout court a aquellos que habían sido principios inspiradores de su constitucionalismo

77 Gazzetta Jonia, n. 3, 16 de julio de 1814, pp. 3-6.

78 Gazzetta Jonia, n. 4, 23 de julio de 1814, p. 2.

79 Tratado de París de 5 de noviembre de 1815. 
-a saber, el self-government, el trial by jury, un responsable government- en aras de un control total de los intereses políticos y comerciales en esa zona del Mediterráneo.

En esa tesitura, cambiaban también la prospectiva en la redacción del periódico, y a partir de las estipulaciones del Tratado de París, paulatinamente perdía aquel talante inicial que le había hecho mirar con ojos favorables las demandas constitucionales procedentes de naciones libres, para transformarse en una publicación oficial atenida a actos de gobierno.

En sustancia, tal publicación se convertía en instrumento de difusión de las numerosas proclamas que "el muy honorable sir Thomas Maitland" daba a la estampa cotidianamente.

La nueva Constitución, presentada al Príncipe en Londres por una diputación del Parlamento jonio, fue integralmente ratificada el 26 de agosto de 1817, y reenviada a Corfú, donde seria promulgada solemnemente el 29 de dicembre.

En el último número de diciembre de 1817 de la Gazzetta Jonia se notificaba a la población la promulgación de la Carta Constitucional, y se daba la noticia de que el nuevo Gobierno se formaría oficialmente el primero de enero de $1818^{80}$.

Si la promulgación de la Constitución encontraba amplio espacio en las páginas del periódico -que dedicaba en su totalidad la entrega de 3 de enero de 1818 a la descripción del ceremonial desplegado en dicha ocasión- esto era posible porque, probablemente, daba cauce a la autocelebración del Alto Lord Protector.

Como es sabido, de hecho, había sido Maitland mismo el redactor del texto de la Carta Constitucional, promoviendo apresuradamente su aprobación, por la Asamblea Legislativa $^{81}$, tal y como se recoge en el testimonio de Andrea Mustoxidi ${ }^{82}$, componente de la misma:

La Constitución fue examinada, discutida y sancionada con admirable obediencia en cuatro sesiones, esto es en cuatro horas, la duración exacta de una representación teatral. Así, no se dejó a la Nación el ejercicio de su derecho de nominación de la Asamblea, ni la Asamblea se reunió para aprobar una Constitución, sino para sancionar la que le era propuesta... ${ }^{83}$.

Con la entrada en vigor de la Constitución, la Gazzetta cambiaba de nombre, convirtiéndose en Gazzetta degli Stati Uniti delle Isole Jonie, manteniendo su papel de periódico del gobierno, apoyatura de la política autoritaria del Lord Protector. No por casualidad pasaba a subrayarse que

80 En la Gaceta aparecía la noticia de que en el Palacio de Corfú, "el $1^{\circ}$ de enero 1818 , el Cuerpo Legislativo se ha reunido a las once horas, y a dicha hora el Lord Alto Comisario del Soberano Protector, habiendo hecho presencia en la Asamblea, tuvo lugar formalmente la instalación del Gobierno de los Estados Unidos de las Islas Jonias, ateniéndose a la Constitución de 1817. Gazzetta Jonia, n. 184, 3 de enero de Gennaio 1818 , p. 1.

81 Acerca del papel desempeñado por Maitland en el proceso genético de la Constitución jonia, RicOTTI, op. cit. (n. 4, 2005), p. 385.

82 Sobre Andrea Mustoxidi puede consultarse E. TIPALdo, Biografia del cavaliere Andrea Mustoxidi, Atenas, Stamperia di P.A. Sakellarios, 1860.

83 Mustoxid, A.: Sulla condizione attuale delle Isole Jonie. Promemoria presentato in agosto 1839 da Andrea Mustoxidi, C.S.M.S.G. e membro del Parlamento degli Stati Joni, Londres, Morton, 1840, p. 4. 
el Senado de los Estados Unidos de las Islas Jonias [...] a empezado a llevar a efecto las importantes tareas que al Ejecutivo han sido confiadas por el Pueblo de estos Estados. A día de hoy sus desvelos y cuidados no tienen otra finalidad que la prosperidad de estos Habitantes. Tal objeto será preocupación constante de sus pensamientos, y de sus esfuerzos: único desahogo para su celo ${ }^{84}$.

Con la creación del protectorado de las Islas Jonias, y la impronta autoritaria impuesta por Maitland a la hora de desenvolver la gobernación de dichas islas, se mostraba palmariamente la determinación británica en cuanto a evitar la reiteración de experiencias similares a las verificadas en Córcega y en Sicilia, reputadas lesivas para la política inglesa. Después de cincuenta años, el 29 de marzo de 1864 con la estipulación del Tratado de Londres, Gran Bretaña se comprometía a transferir a Grecia la soberanía sobre la federación de las Islas Jonias, de manera que el e28 de mayo de ese mismo año, dicho archipiélago pasaba a convertirse en parte integrante del territorio helénico.

Así pues, el nacimiento de los Estados Unidos de las Islas Jonias resulta fundamentalmente excéntrico, y carente de relevancia, respecto a nuestra tesis inicial, sea porque habían venido a menos los presupuestos de la guerra psicológica que la Gran Bretaña había conducido contra Francia, jacobina primero y napoleónica después, sea en fin porque el clima de la inminente Restauración cancelaba, siquiera momentáneamente, las reivindicaciones liberales y nacionales que habían agitado los primeros años del Ochocientos $^{85}$.

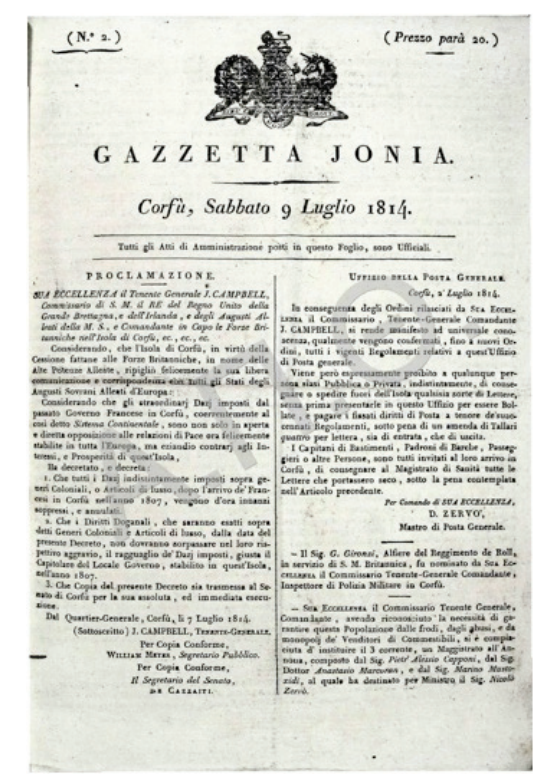

84 Gazzetta degli Stati Uniti delle Isole Jonie, n. 3, 5/17 de enero de 1818.

85 En 2008 tuvo lugar un importante congreso, organizado por la Universidad de Pavía, sobre el tema: Codici e costituzioni nel crocevia mediterraneo. Le fonti del diritto nelle Repubbliche delle Isole Jonie (17971864); las actas, sin embargo, no han sido publicadas en el momento de escribir estas líneas. 


\section{PARA CONCLUIR}

Mediante esta investigación he intentado sintetizar aquellos experimentos constitucionales que, promovidos por la clase política inglesa, y en particular por el ala burkeana de los wighs, tendía a la exportación hacia el área mediterránea de los principios del constitucionalismo británico apoyados fácticamente por una intensa propaganda periodística.

Tales experiencias, maduradas en el Mare Nostrum, desvelaban una estrategia de amplio alcance dirigida a la creación de un auténtico modelo alternativo al constitucionalismo revolucionario y napoleónico. El conflicto de índole militar entre Francia y Gran Bretaña se transformaba rápidamente en una confrontación ideológica entre el constitucionalismo británico y un nuevo absolutismo, el de Napoleón que, como ponía en evidencia Maranini, se presentaba "armado de una legislación adecuada a las condiciones sociales modernas, reconsagrado por parodias plebiscitarias, provisto de instrumentos policiales, administrativos y militares que jamás habrían podido procurarse los reyes absolutos" $" 86$.

Partiendo dal Reino Anglo-Corso de 1794, las iniciativas políticas y diplomáticas promovidas por el gobierno británico se desplegaron durante un ventenio atravesando las islas mayores del Mediterráneo: proyectos de Malta $(1801,1802)$, tentativa fallida en 1812 en Cerdeña, constitución del Reino de Sicilia y, por último, experiencia de los Estados Unidos de las Islas Jonias.

Este trabajo ha puesto en evidencia algunas analogías y persistencias en los sistemas de activación de las diversas fases de estrategia político militar. Una serie casi de principios de "costitución material" con los cuales el gabinete londinense trataba de uniformar los diversos reinos a los que daba vida. Ello se hacía transparente en las "instrucciones" proporcionadas a los comisionados británicos, empezando por Elliot en Córcega y terminando por Thomas Maitland en las Islas Jonias. Se hacían explícitas, de hecho, las tentativas de crear una representación electiva de base propietaria, la tutela de la religión y la defensa de los antiguos derechos de las diversas poblaciones. En otras palabras, como subraya Ricotti,

verdaderamente se trataba de los principios-guía del constitucionalismo burkeano que, con jugados con un amplio sistema de libertades públicas, como la libertad de imprenta y de opinión, el habeas corpus, el "trial of jury", constituirán las líneas de fuerza de la futura proyectística constitucional en el Mediterráneo ${ }^{87}$.

Similitudes se encuentran también en el intento, por parte del gabinete británico, de individualizar un estamento político y burocrático, sustancialmente homogéneo, al cual confiar la organización concreta de las instituciones de gobierno a efectos de orientación de la política interior y exterior, en armonía con los intereses de la "madre patria". Existía además la voluntad de experimentar el posible montaje de modelos constitucionales en territorios de nueva adquisición, en los cuales la influencia in-

\footnotetext{
86 Maranini, G.: Storia del potere in Italia 1848-1967, Florencia, Vallacchi Editore, 1983, p. 65.

87 RicotTi, op. cit. (n. 4, 1998), p. 393.
} 
glesa era sustancialmente precaria y de escaso espesor temporal, territorios a los que daba un rasgo común nada despreciable el hecho de ser islas. Se trataba de momentos de importancia significados, pues, no sólo por la presencia de tropas inglesas en el territorio, sino por la promulgación de una Carta, y lo que es más interesante aquí, por la constitucionalización de la libertad de imprenta.

Como recordaba Benjamin Constant, no existe constitución sin opinión pública y, consecuentemente, no hay opinión pública sin libertad de imprenta. En la construcción de los nuevos Reinos, sin embargo, lo que aperece como evidencia inmediata no es tanto la libertad de imprenta reconocida tout court como los esfuerzos desplegados por Gran Bretaña para crear una opinión pública que fuera favorable. El modelo inglés debía ser reconfigurado como un sistema político-social capaz de realizar una constante y equilibrada composición de los intereses de los diversos estamentos y por tanto del entero cuerpo social: una función que se hacía patente a través de verdaderos y propios instrumentos de propaganda. Del examen comparado de las diversas gacetas puede entresacarse, de hecho, un sutil filo rosso que enlaza entre sí las diversas experiencias constitucionales.

De esta manera, en Córcega se publicaba la Gazzetta Corsa, en Malta aparecían los numerosos periódicos de Vittorio Barzoni, en Cerdeña el Foglio Periodico del Palmedo y, además, la Gazzetta Britannica del taller Del Nobolo de Messina, para llegarse a la Gazzetta Jonia de 1814: instrumentos todos de formación de una opinión pública controlada, favorable en un juego de "guerra psicológica" a una sola potencia en el Mediterráneo, a saber, una Inglaterra refigurada como "exportadora de derechos y libertad". Dichos experimentos propagandísticos, si bien realizados en momentos históricos diversos, mostraban en común características específicas. Ante todo, la mayor parte de los redactores, como hemos tenido ocasión de observar, era por motivos políticos e ideológicos cercana a Inglaterra, si es que no directamente a sueldo de la misma. Su objetivo común era la exaltación de la rubia Albión como modelo ideal de organización política, capaz de mediar, en régimen de libertad, entre instancias aristocráticas e instancias de una naciente burguesía.

Con el denominador común de una intención única -y respecto a tres de ellas incluso resulta visible inmediatamente la identidad del "mittente" al exhibir en el frontispicio el esdo inglés ${ }^{88}$-, esas gacetas tuvieron trayectorias y duraciones diversas, a tenor de la razón de Estado que las apoyaba. Consecuentemente, la Gazzetta Corsa venía publicada sólo durante el bienio 1794-1796; Vittorio Barzoni, a su vez, en Malta, pudo ejercitarse en la actividad de "gacetero" durante casi un decenio; Palmedo, en Cerdeña, vio como su periódico aparecía ligado a la duración de un año, en 1812; El "Impresor Británico" Giovanni Del Nobolo pudo estampar la Gazzetta Britannica, por su parte, y de manera continuada, durante siete años largos; la Gazzetta Jonia, en fin, publicada a partir de 1814, desde el año inmediato perdió su impronta de periódico constitucional para transformarse en papel oficial del gobierno, convirtiéndose luego, en 1818, en la Gazzetta degli Stati delle Isole Jonie.

La trayectoria que había podido observarse, a caballo de los siglo XVIII y XIX, con la Gran Bretaña como protagonista de las mutaciones constitucionales en el Me-

\footnotetext{
88 La referencia es al Giornale di Malta, a la Gazzetta Britannica y a la Gazzetta Jonia.
} 
diterráneo, se concluía con la formación del protectorado inglés sobre las Islas Jonias. Este último experimento, si bien caracterizado por los elementos que se han indicado como esenciales para el nacimiento de una opinión pública atenta e informada (o controlada), como la presencia local inglesa, la promulgación de una carta constitucional (aunque en ésta no se contemplara la constitucionalización de la libertad de imprenta) y la publicación de un periódico, resultaba al concretarse de alguna manera excéntrico respecto a las experiéncias que lo habían precedido. Para empezar, habían venido a menos los presupuestos de la guerra psicológica conducida por Gran Bretaña contra Francia y, luego, el clima de la Restauración había puesto fin, si bien momentáneamente, a las reivindicaciones liberal-nacionales que agitaran los primeros años del Ochocientos. El nacimiento de los Estados Unidos de las Islas Jonias, sustancialmente, representaba el final de la idea del Reino Unido como exportador de libertades constitucionalmente garantizadas, viniendo a configurarse como anticipación concreta del nacimiento de los primeros dominions y de la sucesiva creación de la Commonwealth.

A los intelectuales europeos no les quedaba sino dirigir su mirada hacia la Constitución de Cádiz ${ }^{89}$, elevada a la condición de mito por las generaciones revolucionarias venideras ${ }^{90}$.

89 Sobre el mito de la Constitución de Cádiz, puede verse últimamente, Romano, A.: "Entre revoluciones y constituciones: un modelo constitucional euromediterraneo", en El paradigma del constitucionalismo iberoamericano y latino en nuestra democracia. II Simposio Internacional. La Constitucion de Cadiz de 1812, Guadalajara (México), 2008, pp. 63-74; ID., "Cadice in Italia", en Aguilar, A. (coord.) y BARRAgÁn BARragÁN, J. y otros. (eds.): La Constitucion de Cadiz de 1812, fuente del derecho Europeo y Americano. Relectura de sus principios fundamentales, Ayuntamiento de Cádiz, Oficina Comisariado Cádiz 2012, 2009, pp. 75-82.

$90 \mathrm{Al}$ respecto se remite a De SAlvo, P.: "Civil and political liberties: the debate on early nineteenth century Sicilian press", en Da Cruz Coelho, M. H., Tavares Ribeiro, M. M., (coord. cient.): Parlamentos: a lei, a prática e as representações. Da Idade Média à Actualidade, Lisboa, Assembleia da República, 2010, pp. 455-460; véase, también, Corciulo, M. S.: Una Rivoluzione per la Costituzione, Pescara, Edizioni Scientifiche Abruzzesi, 2009. 